\title{
Isobolographic Analysis of Antiseizure Activity of the GABA Type A Receptor-Modulating Synthetic Neurosteroids Brexanolone and Ganaxolone with Tiagabine and Midazolam
}

\author{
Shu-Hui Chuang and (i)Doodipala Samba Reddy
}

Department of Neuroscience and Experimental Therapeutics, College of Medicine, Texas A\&M University Health Science Center, Bryan, Texas

Received July 23, 2019; accepted December 13, 2019

\begin{abstract}
Epilepsy is often treated with a combination of antiepileptic drugs. Although neurosteroids are potent anticonvulsants, little is known about their combination potential for the treatment of refractory epilepsy. Here, we investigated the combination efficacy of neurosteroids allopregnanolone (AP, brexanolone) and ganaxolone (GX) with the GABA-reuptake inhibitor tiagabine (TG) or the benzodiazepine midazolam (MDZ) on tonic inhibition in dentate gyrus granule cells and seizure protection in the hippocampus kindling and $6-\mathrm{Hz}$ seizure models. Isobolographic analysis indicated that combinations of GX and TG or AP and TG at three standard ratios (1:1, 3:1, and 1:3) displayed significant synergism in augmenting tonic inhibition. In pharmacological studies, GX, $\mathrm{AP}$, and TG produced dose-dependent antiseizure effects in mice $\left(E D_{50}=1.46,4.20\right.$, and $0.20 \mathrm{mg} / \mathrm{kg}$, respectively). The combination of $G X$ and $T G$ at the fixed ratio of $1: 1$ exerted the greatest combination index $(\mathrm{Cl}=0.53)$, indicating strong synergistic interaction in seizure protection. In addition, combination regimens of $A P$ and $T G$ showed robust synergism for seizure protection $(\mathrm{Cl}=0.4)$. Finally, combination regimens of $\mathrm{GX}$ and MDZ elicited synergistic $(\mathrm{Cl}=0.6)$ responses for seizure protection. These results demonstrate striking synergism of
\end{abstract}

neurosteroids and TG combination for seizure protection, likely because of their effects at extrasynaptic GABA type A (GABA-A) receptors from TG-induced elevation in GABA levels. Superadditive antiseizure activity of neurosteroid-MDZ combinations may stem from their actions at both synaptic and extrasynaptic GABA-A receptors. Together, these findings provide a potential mechanistic basis for combination potential of neurosteroids with TG or benzodiazepines for the management of refractory epilepsy, status epilepticus, and seizure disorders.

\section{SIGNIFICANCE STATEMENT}

This paper investigates for the first time the potential synergistic interactions between two neurosteroids with anticonvulsant properties, allopregnanolone (brexanolone) and the very similar synthetic analog, ganaxolone, and two conventional antiepileptic drugs active at GABA type A receptors: the GABA-reuptake inhibitor tiagabine and a benzodiazepine, midazolam. The results demonstrate a synergistic protective effect of neurosteroidtiagabine combinations, as well as neurosteroid-midazolam regimens in seizure models.

\section{Introduction}

Antiepileptic drugs (AEDs) are the mainstay for the treatment of epilepsy, a chronic neurologic disorder that affects nearly 65 million people worldwide (Thurman et al., 2011; Hesdorffer et al., 2013). AEDs are the most effective interventions for suppressing the occurrence of seizures; however, approximately $30 \%$ of epilepsy patients are unresponsive to current AEDs when used in monotherapy. Consequently, a polypharmacy with combination of two or more AEDs is used to improve seizure control in persons with refractory epilepsy. Drugs given in combination may produce effects that are additive or synergistic, which is estimated using

This research was supported by the CounterACT Program, National Institutes of Health, Office of the Director and the National Institute of Neurological Disorders and Stroke [Grant U01 NS083460].

The authors declare no competing financial interests.

https://doi.org/10.1124/jpet.119.261735. isobolograms (Tallarida, 2006), including select AED combinations (Łuszczki and Czuczwar, 2004; Kwan and Brodie, 2006; Łuszczki, 2008a,b). Neurosteroids are developed as novel AEDs for epilepsy (Reddy and Estes, 2016). Combination of a neurosteroid with a GABAergic AED may enhance seizure control in refractory epilepsy.

GABA type A (GABA-A) receptors are the prime targets of AEDs such as benzodiazepines, neurosteroids, and indirectly tiagabine (TG). There are two subtypes of GABA-A receptors in the brain: synaptic and extrasynaptic receptors (Chuang and Reddy, 2018a). Synaptic GABA-A receptors generate a transient inhibitory postsynaptic current, whereas extrasynaptic GABA-A receptors generate a tonic inhibitory current that regulates neuronal network excitability. Extrasynaptic GABA-A receptors typically contain either $\delta$ or $\alpha 5$ subunits in combination with $\beta 2$ or $\beta 3$ subunits and elicit the basal inhibitory tone referred to as tonic inhibition (Bianchi and Macdonald, 2003; Coulter and Carlson, 2007; Glykys et al., 2008).

ABBREVIATIONS: AD, afterdischarge; AED, antiepileptic drug; AP, allopregnanolone ( $3 \alpha$-hydroxy-5 $\alpha$-pregnan-20-one); $\mathrm{Cl}$, combination index; $\mathrm{CL}$, confidence limit; DGGC, dentate gyrus granule cell; GABA-A, GABA type A; GX, ganaxolone (3 $\alpha$-hydroxy-3 $\beta$-methyl-5 $\alpha$-pregnan-20-one); MDZ, midazolam; SE, status epilepticus; TG, tiagabine. 
Extrasynaptic $\delta$ GABA-A receptors are expressed in a cell-typespecific fashion in key brain areas such as hippocampus, thalamus, cerebellum, and amygdala (Jutila et al., 2002; Mortensen et al., 2012). Tonic inhibition plays a critical role in epilepsy (Carver et al., 2014; Reddy, 2018; Reddy et al., 2019). Neurosteroids such as allopregnanolone (AP, $3 \alpha$-hydroxy-5 $\alpha$-pregnan-20-one), which was renamed recently as brexanolone, are potent allosteric agonists of GABA-A receptors, especially extrasynaptic $\delta \mathrm{GABA}-\mathrm{A}$ receptors (Chuang and Reddy, 2018a). AP has been shown to have robust anticonvulsant and anxiolytic activity (Rupprecht, 2003; Belelli and Lambert, 2005; Carver and Reddy, 2013; Brown et al., 2015; Porcu et al., 2016; Chuang and Reddy, 2018b). In 2019, brexanolone was approved by the Food and Drug Administration for postpartum depression (Meltzer-Brody et al., 2018).

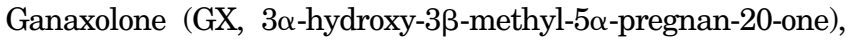
a synthetic analog of $\mathrm{AP}$, is a broad-spectrum anticonvulsant agent. Like AP, GX is a powerful allosteric modulator of synaptic and extrasynaptic GABA-A receptors (Carter et al., 1997; Chuang and Reddy, 2018b). GX is undergoing clinical trials for refractory epilepsy, pediatric genetic epilepsies, and status epilepticus (SE) (Nohria and Giller, 2007; Pieribone et al., 2007; Reddy and Rogawski, 2010, 2012; Porcu et al., 2016; Ligsay et al., 2017). However, the antiepileptic potential of GX or other neurosteroids in combination with current AEDs has not yet been widely investigated. It is suggested that a combination therapy utilizing pair compounds with distinct GABAergic mechanism might provide additive or synergistic therapeutic efficacy in epilepsy with minimal off-target side effects. Tiagabine (TG) is an adjunct AED for partial seizures (Goldenberg, 2010). TG, a GABA-reuptake inhibitor, increases GABA levels in the synaptic cleft by selective blockade of the GABA transporter type 1 or GAT1 (Adkins and Noble, 1998; Meldrum and Chapman, 1999). The major limitations of TG include lack of robust antiseizure efficacy and adverse effects such as dizziness, nervousness, seizures, and tremors. It is suggested that a combination of TG with neurosteroids might be an effective antiseizure regimen because TG would be expected to boost the pharmacodynamic efficiency of neurosteroids in augmenting GABAergic inhibition.

To evaluate the effect of neurosteroids and TG combinations, we used the isobolographic analysis, a well-accepted approach for the assessment of drug interactions (Grabovsky and Tallarida, 2004; Łuszczki, 2008a,b). It typically includes two types: type I is used to evaluate drugs that are fully active, wheras type II is used when one of the drugs tested has no effect (Berenbaum 1989). Drug combination analysis with isobologram is a valuable strategy to differentiate the exact type of interactions among drugs tested as synergistic, additive, or antagonistic (Grabovsky and Tallarida 2004; Tallarida 2006, 2007).

In this study, we sought to investigate the combination interactions between neurosteroids and TG or neurosteroid and midazolam (MDZ) on tonic inhibition in hippocampus slices and antiseizure effects in mouse seizure models. We tested the synergistic interaction between AP (brexanolone, drug approved by the Food and Drug Administration) and TG regimens. Our studies demonstrate a synergistic protective effect of neurosteroid-TG combinations and neurosteroid-MDZ regimens in seizure models.

\section{Materials and Methods}

Animals. Experiments were conducted in young adult male mice (2-3 months old) with a C57BL/6 background strain. Mice were housed four per cage under standard laboratory conditions with a 12-hour light/dark cycle. The animals were cared for in compliance with the guidelines in the National Institutes of Health Guide for the Care and Use of Laboratory Animals. Animal procedures were conducted in compliance with a protocol approved by the Institutional Animal Care and Use Committee. The current study was conducted in male mice only. Female groups were not incorporated in the study design to limit the complex interpretation of the outcomes due to the impact of estrous cycle and potential sex-differences in antiseizure activity of neurosteroids (Wu et al., 2013; Reddy et al., 2019).

Tonic Current Recordings in Hippocampus Slices. Tonic currents were recorded by standard patch-clamp electrophysiology methods as described previously (Maguire et al., 2005; Mtchedlishvili and Kapur, 2006; Maguire and Mody, 2008; Wu et al., 2013; Carver et al., 2014; Carver and Reddy, 2016; Chuang and Reddy, 2018b). Adult male mice were anesthetized with isoflurane, and the brains were rapidly excised and placed in ice-cold artificial cerebrospinal fluid buffer composed of (in millimolars): 0.3 kynurenic acid (Tocris Bioscience, Bristol, UK), $126 \mathrm{NaCl}, 3 \mathrm{KCl}, 0.5 \mathrm{CaCl}_{2}, 5 \mathrm{MgCl}_{2}, 26$ $\mathrm{NaHCO}_{3}, 1.25 \mathrm{NaH}_{2} \mathrm{PO}_{4}, 11$ glucose (pH adjusted to $7.35-7.40$ with $95 \% \mathrm{O}_{2}$ and $\left.5 \% \mathrm{CO}_{2}, 305-315 \mathrm{mOsm} / \mathrm{kg}\right)$. Transverse slices $(320-\mu \mathrm{m}$ thickness) of the hippocampus were obtained with a vibratome in $3.5^{\circ} \mathrm{C}$ artificial cerebrospinal fluid (model 1500 with 900 Refrigeration System; Leica Microsystems, Inc., Bannockburn, IL). Hippocampal dentate gyrus granule cells (DGGCs) were identified with an Olympus BX51 microscope with a $40 \times$ water-immersion objective, infrareddifferential interference contrast optics, and video camera. Hippocampus slices were incubated at $28^{\circ} \mathrm{C}$, and recordings were conducted at room temperature $\left(22-24^{\circ} \mathrm{C}\right)$ with a holding potential of $-65 \mathrm{mV}$ as described by other groups (Vicini et al., 2002; Scimemi et al., 2006; Nani et al., 2013; Gong and Smith, 2014). The physiologic bath solution was composed of (in millimolars): $124 \mathrm{NaCl}, 3 \mathrm{KCl}, 1.5 \mathrm{MgSO}_{4}, 2.4 \mathrm{CaCl}_{2}, 1.25$ $\mathrm{NaH}_{2} \mathrm{PO}_{4}, 26 \mathrm{NaHCO}_{3}$, and 10 glucose ( $\mathrm{pH}$ adjusted to 7.4 with $\mathrm{NaOH}$, osmolarity, 295-305 $\mathrm{mOsm} / \mathrm{kg}$ ). The pipette tips were filled with a cesium pipette solution containing (in millimolars): $124 \mathrm{CsCl}$, 20 tetraethylammonium-chloride, $2 \mathrm{MgCl}_{2}, 10$ EGTA, 10 HEPES, 0.1 GTP, 4 ATP, and 5 lidocaine $N$-ethyl bromide (QX-314) (pH adjusted to 7.2 with $\mathrm{CsOH}$, osmolarity, 295-305 mOsm/kg). Currents were acquired with an Axopatch 200B amplifier (Molecular Devices, Sunnyvale, CA). The membrane capacitance, series, and input resistance of the recordings were recorded by applying a $5-\mathrm{mV}$ (100-millisecond) depolarizing voltage. Signals were low-pass filtered at $2 \mathrm{kHz}$ and digitized at $10 \mathrm{kHz}$ with the Digidata $1440 \mathrm{~A}$ system. Tonic currents recorded from a single neuron were normalized to membrane capacitance as tonic current density ( $\mathrm{pA}$ per $\mathrm{pF}$ ). Drugs were allowed 4 minutes to perfuse into the bath chamber and slice before measurements were obtained. The perfusion rate was maintained at $2 \mathrm{ml} / \mathrm{min}$. Tonic current was measured and averaged in 100 milliseconds each epoch with 1-second intervals between 30 epochs. Four to six mice were used to obtain an adequate sample size for each group.

6-Hz Seizure Model. The $6-\mathrm{Hz}$ mouse model of partial seizures was used as previously described (Reddy et al., 2015). Mice were electrically stimulated via cornea for 0.2-millisecond-duration monopolar low-frequency rectangular pulses at $6-\mathrm{Hz}$ for 3 seconds (World Precision Instruments, Sarasota, FL). The current value causing seizures in $50 \%$ of animals was determined by administering different current intensities in the range of 6-44 $\mathrm{mA}$ to a group of control animals. A current intensity at $38 \mathrm{~mA}$ was determined to elicit seizures in $100 \%$ of the population of male mice and was delivered as the standardized intensity for the in vivo studies of combination therapy. The ocular anesthetic tetracaine $(0.5 \%)$ drops were applied to each eye 10 minutes before stimulation. The corneal electrodes were wetted with $0.9 \%$ saline solution immediately prior to stimulation. Animals were manually restrained for stimulation and immediately released into a chamber for behavioral observation. Test drugs were administered 15 minutes before stimulation. The duration of seizure activity ranged from 20 to 60 seconds in vehicle-treated mice. Animals were considered to be protected if they resumed normal 
exploratory behavior within 10 seconds of the stimulation. Six to eight animals were used for each dose of treatment.

Hippocampus Kindling Seizure Model. Experimental procedures and drug treatment protocols in the hippocampus kindling model were conducted as described previously (Reddy and Mohan, 2011; Reddy et al., 2015). Mice displaying consistent generalized (stage 5) seizures were used for drug testing. The electrographic afterdischarge (AD) was recorded using the Grass CP511 preamplifier system (Astro-Med, West Warwick, RI). The behavioral seizure stages were scored based on the Racine's scale (Racine, 1972): stage $0=$ no response or behavior arrest; stage $1=$ chewing or facial twitches; stage $2=$ chewing and head nodding; stage $3=$ forelimb clonus; stage $4=$ bilateral forelimb clonus and rearing; and stage $5=$ bilateral forelimb clonus/rearing and falling. Test drugs were given 15 minutes before kindling stimulations.

Isobolographic Analysis of Drug-Drug Interactions. Interactions between neurosteroids and TG or MDZ against 6-Hz-induced seizures were examined using established methodology as described previously (Łuszczki, 2008a,b). Briefly, the $\mathrm{ED}_{50}$ of each drug administered alone in the $6-\mathrm{Hz}$ seizure model was first determined by using log-probit linear regression analysis (Litchfield and Wilcoxon, 1949). Next, the theoretical additive $\mathrm{ED}_{50}$ add values \pm S.E.M. for the mixtures of tested drugs at three fixed ratios (1:1, 1:3, and 3:1; the most commonly used drug-dose ratio combinations for the evaluation of drug interactions) were calculated. The $\mathrm{ED}_{50}$ add value is a total additive dose of the two drugs in the mixture, exerting theoretically a $50 \%$ protection against $6-\mathrm{Hz}$-induced seizures. The $\mathrm{ED}_{50}$ mix values are experimentally determined total doses of a mixture of two tested drugs administered at a fixed-ratio combination sufficient for $50 \%$ protection against $6-\mathrm{Hz}-$ induced seizures and were derived from the seizure protection exerted by each mixture at 1:3, 1:1, and 3:1 .

For the analysis of electrophysiological tonic currents, the isobologram method was adapted to study the interactions between neurosteroids and TG or MDZ on the tonic inhibition. We used the $\mathrm{EF}_{\text {twofold }}$ (effective functional concentration of drug) values that represent the effective functional concentration of drug (nanomolars) required to double the basal tonic response in DGGCs. Briefly, the $\mathrm{EF}_{\text {twofold }}$ values of tested drugs were deduced from their concentration-response curves. The theoretical $\mathrm{EF}_{\text {twofold }}\left(\mathrm{EF}_{\text {twofold add }}\right)$ values for mixtures were calculated and tested in DGGCs to quantify the contribution of each drug to the overall effects. The experimental $\mathrm{EF}_{\text {twofold }}\left(\mathrm{EF}_{\text {twofold mix }}\right)$ values were derived from the tonic current modulation of each mixture. The isobolograms were plotted, and the theoretical and experimentally determined $\mathrm{EF}_{\text {twofold }}$ values of mixtures were compared .

Here, the isobolographic analysis was performed to ascertain the effect of combination, which is based on the concept of "dose equivalence." This isobologram method is the "gold standard" for the evaluation of interactions between drugs, which allows their stratification as supra-additive (synergistic), additive, and subadditive (antagonistic) drugs (Tallarida, 2006). In isobolography, it is accepted that half of the $\mathrm{ED}_{50}$ dose of a first drug plus half of the $\mathrm{ED}_{50}$ dose of a second drug should be as therapeutically effective as a full dose of each drug administered separately. This concept of adding fractions of the effective doses of AEDs is the fundamental rule underlying the isobolographic analysis (Loewe, 1953; Berenbaum, 1989; Tallarida, 2000). The interaction of two or more drugs to produce a combined effect is described by the interaction index I (Berenbaum 1977):

$$
I=D 1 / M 1+D 2 / M 2
$$

where, $D 1$ and $D 2$ are concentrations of drugs 1 and 2 that produce a certain effect if applied together; $M 1$ and $M 2$ are the median concentrations that produce the same effect when given alone. Consequently, for deriving the $50 \%$ seizure protection, eq. 1 can be expressed as

$$
I=D 1 / E D_{50,1}+D 2 / E D_{50,2}
$$

Here, $E D_{50,1}$ and $E D_{50,2}$ are the $E D_{50}$ values of drug 1 and drug 2 alone. $D 1$ and $D 2$ are the doses of drugs 1 and 2, respectively, which also produce $50 \%$ protection when given together. This general method has been developed based on the analysis of each drug alone and the simulation of the combined action response based on the Loewe additivity theory (Loewe, 1953). For drugs showing an interaction, eq. 1 is adapted and advanced into defining a combination index (CI), indicating type and amount of interaction between two drugs with target experimental outcome (Chou and Talalay, 1983).

$$
C I=D 1 / M 1+D 2 / M 2,
$$

with $>1$ for antagonism, $=1$ for additivity, and $<1$ for synergy.

The CI can take values between 1 and infinity for antagonism, and it runs between 0 and 1 for synergy. The interaction index underlies one of the most widely used graphical representations of drug synergism and antagonism, the isobologram (Fig. 1). The isobolograph illustrates typical subadditive (antagonistic) and superadditive (synergistic) isoboles. The doses of drugs $\mathrm{A}$ and $\mathrm{B}$ give abscissa and ordinate, respectively, and the effect of drug combinations is plotted as a graph (Fig. 1). The effects of each drug alone $\left(\mathrm{ED}_{50}\right)$ can be read from the axes. The isobologram shows an effect, such as anticonvulsant $\mathrm{ED}_{50}$, and which drug concentration is needed to achieve this effect. Overall, to simplify the notation of interactions in isobolography, the drug doses were administered in fixed-ratio combinations (1:3, 1:1, and 3:1) and reflect fractions of $\mathrm{ED}_{50}$ values denoted for the drugs used separately. The isobologrambased CI calculations were obtained to identify additive from synergistic interactions.

Drugs and Reagents. All chemicals used in the study were acquired from Sigma-Aldrich unless otherwise specified. AP and GX were prepared as $2 \mathrm{mM}$ stock solutions in dimethyl sulfoxide for

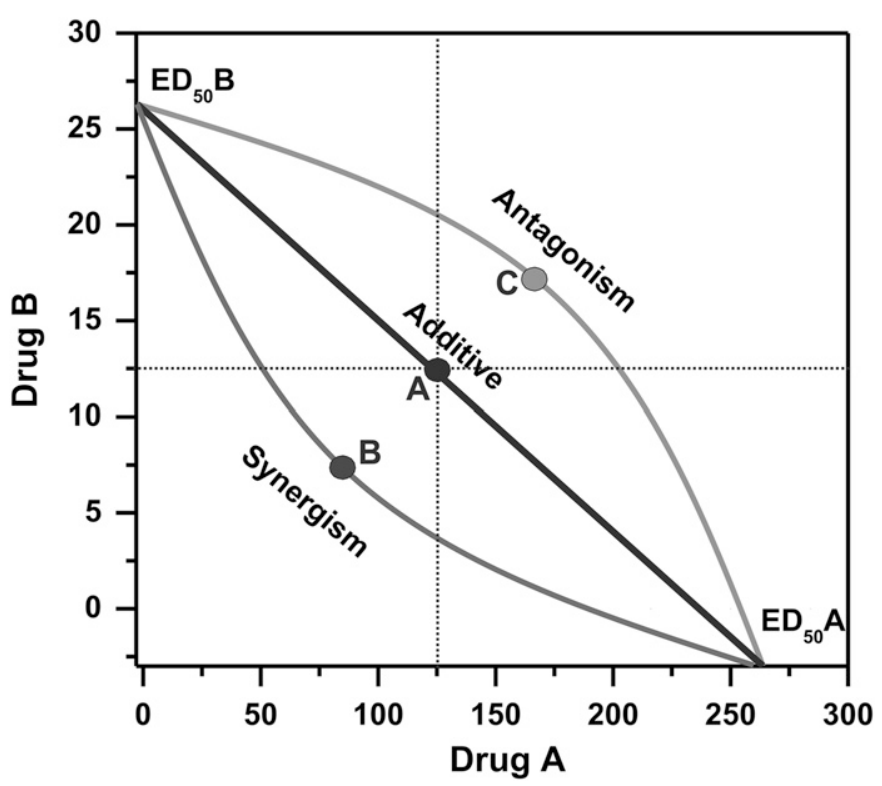

Fig. 1. Isobologram-based characterization of drug combinations. The isobologram is considered a gold-standard procedure for studying drug combination analysis (Tallarida, 2000, 2006, 2007). The $x$ - and $y$-axis units are the doses of drugs $\mathrm{A}$ and $\mathrm{B}$. The solid black line connects doses that produce the same effect of certain examined responses $\left(\mathrm{ED}_{50}\right.$ line), such as seizure protection. From additivity (A), the combination of drug A with drug $\mathrm{B}$ would produce $50 \%$ protection (point A). If $50 \%$ protection is achieved at lower doses of the two drugs, the drugs would exhibit synergism (point B). If the observed effect by the combination is less than $50 \%$, drugs $\mathrm{A}$ and $\mathrm{B}$ would interact in an antagonistic way (point $\mathrm{C}$ ). The dashed lines are drawn to enhance the recognition of symmetry for additive isobole responses. In practical terms, fixed drug dose ratios are tested in the standard combinations $(1: 3,1: 1,3: 1)$, and $\mathrm{ED}_{50}$ values are determined for the mixture. 
TABLE 1

The values of current $(\mathrm{pA})$ and current density $(\mathrm{pA}$ per $\mathrm{pF})$ potentiation by each mixture of drug combinations

\begin{tabular}{lccc}
\hline & Current Shift $(\mathrm{pA})$ & $\begin{array}{c}\text { Current Density } \\
(\mathrm{pA} / \mathrm{pF})\end{array}$ & Sample Size $(n)$ \\
\hline Basal & $10.8 \pm 1.6$ & $0.31 \pm 0.06$ & 12 \\
EF $_{\text {twofold }}$ & $21.6 \pm 3.2$ & $0.62 \pm 0.12$ & \\
GX:TG $=1: 3$ & $59.9 \pm 12.8$ & $1.28 \pm 0.25$ & 7 \\
GX:TG $=1: 1$ & $61.3 \pm 10.4$ & $1.38 \pm 0.20$ & 7 \\
GX:TG $=3: 1$ & $30.2 \pm 4.3$ & $0.70 \pm 0.09$ & 8 \\
AP:TG $=1: 3$ & $56.5 \pm 15.5$ & $1.37 \pm 0.30$ & 6 \\
AP:TG $=1: 1$ & $51.2 \pm 9.0$ & $1.22 \pm 0.17$ & 6 \\
AP:TG $=3: 1$ & $129.5 \pm 32.1$ & $3.12 \pm 0.78$ & 6 \\
GX:MDZ = 1:3 & $31.5 \pm 8.6$ & $0.66 \pm 0.17$ & 6 \\
GX:MDZ $=1: 1$ & $32.0 \pm 8.4$ & $0.66 \pm 0.18$ & 6 \\
GX:MDZ $=3: 1$ & $51.1 \pm 11.3$ & $1.08 \pm 0.23$ & 6 \\
\hline
\end{tabular}

$n$, cell number of each group and concentration.

electrophysiology experiments. Stock solutions were diluted in the external perfusion solution to the desired concentration for electrophysiological use. The concentration of dimethyl sulfoxide in final solution was less than $1 \%$. AP was purchased from Steraloids (Newport, RI), and GX was purchased from Tocris. Tetrodotoxin was acquired from Calbiochem (Billerica, MA). MDZ was purchased from Akorn (Lake Forest, IL). AP and GX were made in $15 \% \beta$-cyclodextrin solution for in vivo study. Drugs were given subcutaneously in a volume equivalent to $1 \%$ of the body weight of the animals.
Statistical Analysis. In electrophysiology studies, data were expressed as means \pm S.E.M. In slice electrophysiology studies, concentration-response curves were subjected to nonlinear, logistic fitting. A curve fitting was applied for concentration responses that achieved a plateau at maximal levels. Comparisons of statistical significance of data were made using a Student's $t$ test. In pharmacological studies, the percent protection of mice against 6 $\mathrm{Hz}$-induced seizures and, subsequently, dose-response relationship lines were fitted using log-probit linear regression analysis according to Litchfield and Wilcoxon (Litchfield and Wilcoxon, 1949). The $\mathrm{ED}_{50}$ values with their $95 \%$ confidence limits (CLs) were calculated by computer-assisted log-probit analysis according to the Litchfield and Wilcoxon procedure. First, the dose-response relationships of test drugs for target outcomes were subjected to the test for parallelism, an essential condition for characterizing AED interactions with isobolography. Because the dose-response relationship for GX and TG were parallel in this study, the type I isobolographic analysis for parallel dose-response relationship lines was used. Statistical evaluation of isobolographic interactions was performed by the use of Student's $t$ test to detect the differences between the experimentally derived $\left(\mathrm{ED}_{50} \mathrm{mix}\right)$ and theoretical additive $\left(\mathrm{ED}_{50}\right.$ add $)$ values (Tallarida, 2000; Łuszczki, 2008a,b). Comparison of the differences in behavioral seizure stage between groups was made with the nonparametric Kruskal-Wallis test followed by the Mann-Whitney $U$ test. The differences in means of the $\mathrm{AD}$ duration between groups were compared with oneway ANOVA, followed by Student's $t$ test. The criterion for statistical difference was $P<0.05$.
A

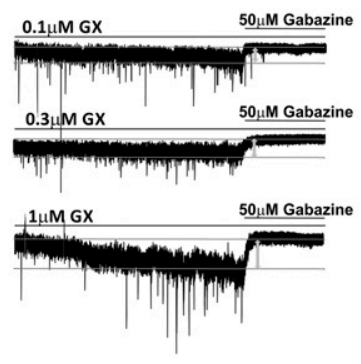

B

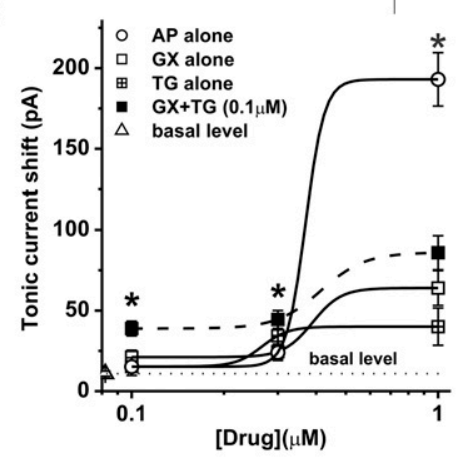

D

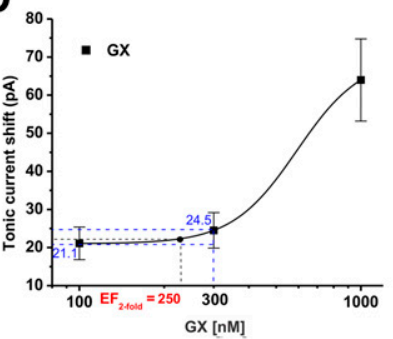

E

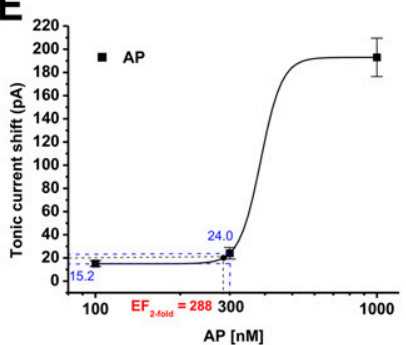

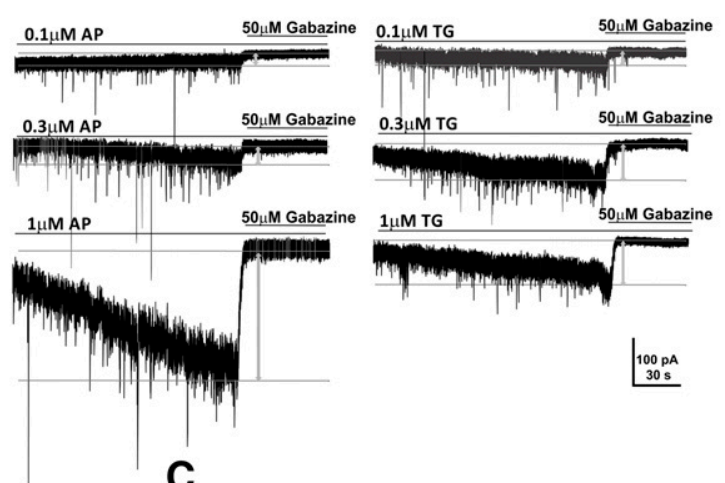

C

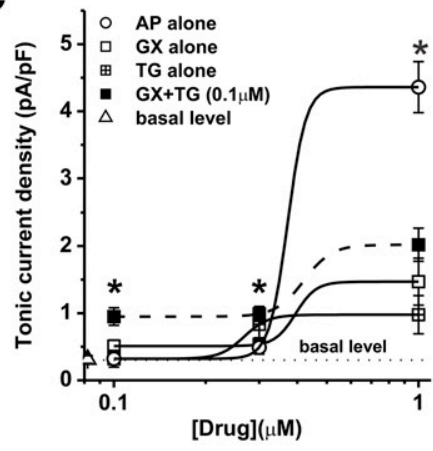

$\mathbf{F}$

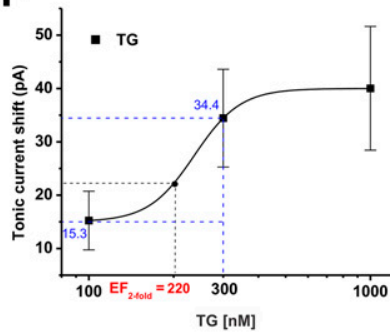

Fig. 2. Ganaxolone (GX) and tiagabine (TG) combination significantly potentiates tonic currents in the hippocampal DGGCs compared with GX alone, indicating a possible synergistic interaction. (A) Representative whole-cell, voltage-clamp recordings of tonic currents in DGGCs in response to GX, allopregnanolone (AP), or TG. Concentration responses for tonic current shift (B) and tonic current density $(\mathrm{C})$ in response to $\mathrm{GX}, \mathrm{AP}$, TG, or GX + TG combination in DGGCs. (D-F) Concentration-response curves illustrating the $\mathrm{EF}_{\text {twofold }}$ values of $\mathrm{GX}, \mathrm{AP}$, and TG. $* P<0.05$ vs. GX alone $(n=6-8$ cells per group). 
TABLE 2

Isobolographic analysis showing theoretical $\left(\mathrm{EF}_{\text {twofold add }}\right)$ and experimentally determined $\left(\mathrm{EF}_{\text {twofold mix }}\right)$ values of $\mathrm{GX}$ and TG combinations on tonic current potentiation in DGGCs

\begin{tabular}{|c|c|c|c|c|c|c|c|c|c|}
\hline AED Combination & Fixed Ratio & \multicolumn{3}{|c|}{$\mathrm{GX}+\mathrm{TG}=\mathrm{EF}_{\text {twofold mix }}(\mathrm{nM})$} & $n_{\text {mix }}$ & \multicolumn{3}{|c|}{$\mathrm{EF}_{\text {twofold add }}=\mathrm{GX}+\mathrm{TG}(\mathrm{nM})$} & \multirow{2}{*}{$\frac{n_{\text {add }}}{6}$} \\
\hline $\mathrm{GX}+\mathrm{TG}$ & $1: 3$ & 22.6 & 59.6 & $82.2 \pm 24.2$ & 7 & $227.5 \pm 40.8$ & 62.5 & 165 & \\
\hline $\mathrm{GX}+\mathrm{TG}$ & $1: 1$ & 44.1 & 38.8 & $83.0 \pm 18.5$ & 7 & $235 \pm 38.5$ & 125 & 110 & 6 \\
\hline $\mathrm{GX}+\mathrm{TG}$ & $3: 1$ & 134.3 & 39.4 & $173.6 \pm 20.5$ & 8 & $242.5 \pm 36.3$ & 187.5 & 55 & 6 \\
\hline
\end{tabular}

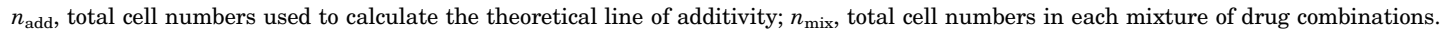

\section{Results}

Synergistic Effects of GX and TG Coapplication on Extrasynaptic $\delta$ GABA-A Receptor-Mediated Tonic Inhibition in Hippocampal DGGCs. To characterize the interactions of neurosteroids with clinical GABAergic agent TG on extrasynaptic $\delta \mathrm{GABA}-\mathrm{A}$ receptor-mediated tonic currents, we first recorded tonic current potentiation by AP, GX, or TG alone $(0.1-1 \mu \mathrm{M})$ in DGGCs from hippocampus slices. Tonic currents were isolated in the presence of the $N$-methyl-D-aspartic acid receptor antagonist (APV, DL-2-amino-5-phosphonopentanoic acid; $40 \mu \mathrm{M}$ ), the $\alpha$-amino-3-hydroxy-5-methyl-4-isoxazolepropionic acid receptor antagonist (DNQX, 6,7-dinitroquinoxaline2,3-dione; $10 \mu \mathrm{M}$ ), and the sodium channel blocker (tetrodotoxin, $0.5 \mu \mathrm{M})$ in the bath solution by using whole-cell patch-clamp electrophysiology. Four minutes after the application of test drugs, a GABA-A receptor antagonist (gabazine, $50 \mu \mathrm{M}$ ) was perfused to determine the total tonic current shift. Current density (pA per $\mathrm{pF}$ ) of each cell was obtained by normalizing the tonic current shift with the cell capacitance. The basal level of tonic currents in DGGCs was $10.8 \pm 1.6 \mathrm{pA}$ (Table 1). As shown in Fig. 2, A-C, AP $(0.1-1 \mu \mathrm{M})$ and GX $(0.1-1 \mu \mathrm{M})$ elicited direct tonic current activation in DGGCs in a concentration-dependent manner, as consistent with previous report (Chuang and Reddy, 2018b). The Hill slope of the concentration-response curve of $\mathrm{AP}$ is 2.25, whereas the Hill slopes of the concentration-response curves of GX and TG + GX are 1.57 and 1.33, respectively. AP at $1 \mu \mathrm{M}$ elicited greater tonic current response than GX, which is consistent with its greater relative potency than GX. Synaptic currents observed during tonic inhibition studies are also greater, especially after the application of AP. These differences are typical of the experimental findings with GX and AP, especially because of their apparent differences in efficacy at activating the extrasynaptic GABA-A receptors (Carver et al., 2016; Chuang and Reddy, $2018 \mathrm{~b})$. The tonic current potentiation by TG $(0.1-1 \mu \mathrm{M})$ in the absence of GABA was shown in Fig. 2, B and C. We then coapplied GX $(0.1-1 \mu \mathrm{M})$ with TG at $0.1 \mu \mathrm{M}$ and recorded the combination effects of GX and TG on tonic inhibition. The potentiation of tonic currents by GX + TG was significantly greater compared with GX alone, indicating possible additive or synergistic effects of combination regimen (tonic current shift: $0.1 \mu \mathrm{M}$ or $0.3 \mu \mathrm{M} \mathrm{GX}+0.1 \mu \mathrm{M}$ TG, $P=0.018$ and 0.020 , respectively; current density, $0.1 \mu \mathrm{M}$ or $0.3 \mu \mathrm{M} \mathrm{GX}+0.1 \mu \mathrm{M}$ TG, $P=0.019$ and 0.024 , respectively; $n=6-8$ cells per group).

To elucidate the precise interaction between GX and TG, we performed the isobolographic analysis, a commonly used method to classify drug interactions as antagonistic, additive, or synergistic by utilizing fixed-ratio drug combinations in

B

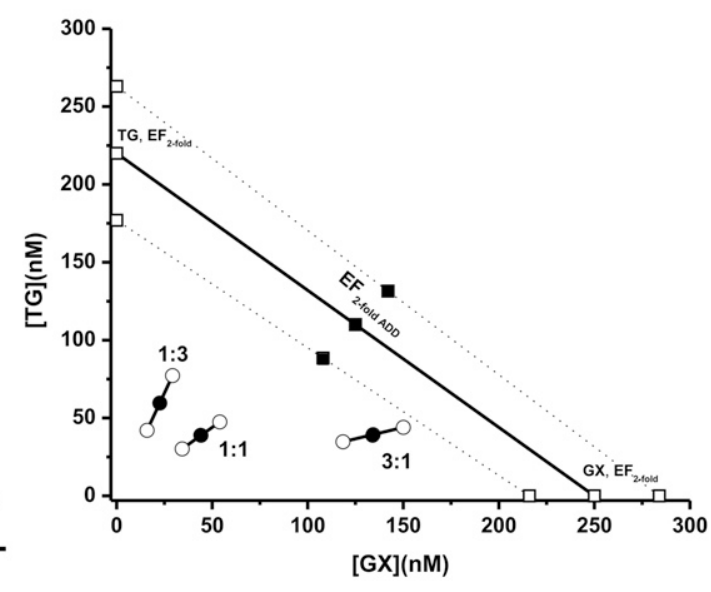

Fig. 3. Synergistic interactions between GX and TG of all combinations tested on tonic current potentiation. (A) Representative whole-cell recordings of tonic currents in DGGCs in response to combinations of GX and TG. (B) Isobologram showing interactions between GX and TG in tonic current potentiation in DGGCs. The $\mathrm{EF}_{2}$ for GX $(250 \mathrm{nM})$ is plotted graphically on the $x$-axis, whereas the $\mathrm{EF}_{2}$ for TG (220 nM) is plotted graphically on the $y$-axis. The distances between open-square points on the $x$ - and $y$-axes represent the 95\% CLs for the drugs treated alone. The straight line connecting these two $\mathrm{EF}_{2}$ values on the graph represents the theoretical line of additivity for a continuum of different fixed concentration ratios, whereas the dashed lines represent the theoretical additive $95 \% \mathrm{CLs}_{\text {of }} \mathrm{EF}_{2}$ values. $\mathrm{EF}_{2}$ denotes the concentration needed to achieve 2-fold potentiation of endogenous basal tonic current $\left(10.8 \pm 1.6 \mathrm{pA} ; 0.31 \pm 0.06 \mathrm{pA} / \mathrm{pF}\right.$ ). The black circles depict the experimentally derived $\mathrm{EF}_{2}$ values (with $95 \%$ CLs as error bars) for the total concentration expressed as the proportion of GX and TG that produced 2-fold potentiation of basal tonic currents. The experimental $\mathrm{EF}_{2}$ values of the mixture of GX + TG for the entire fixed ratio are placed below the theoretical line of additivity, indicating the tendency toward synergism. 
A

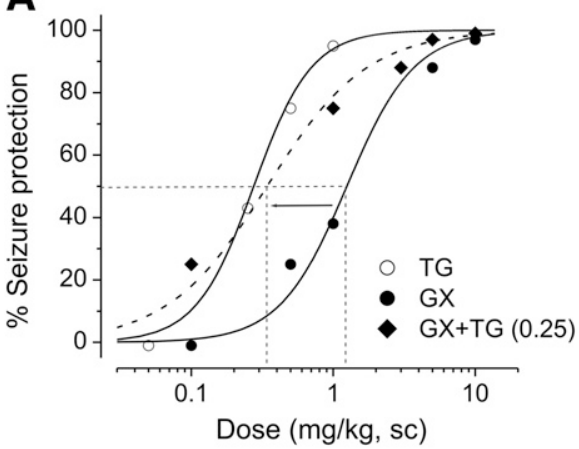

C

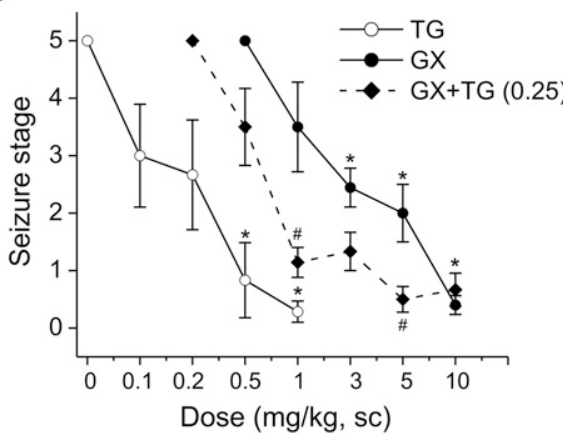

E

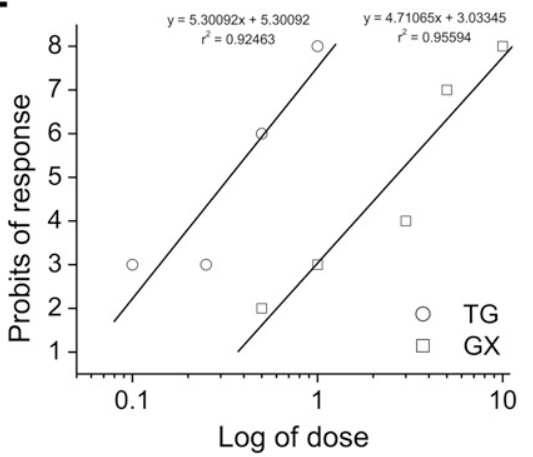

B

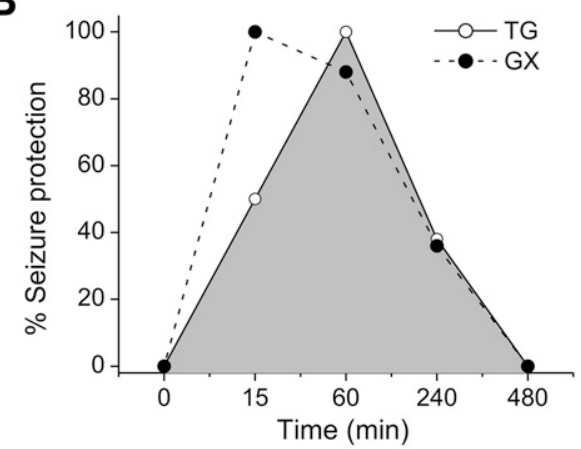

D

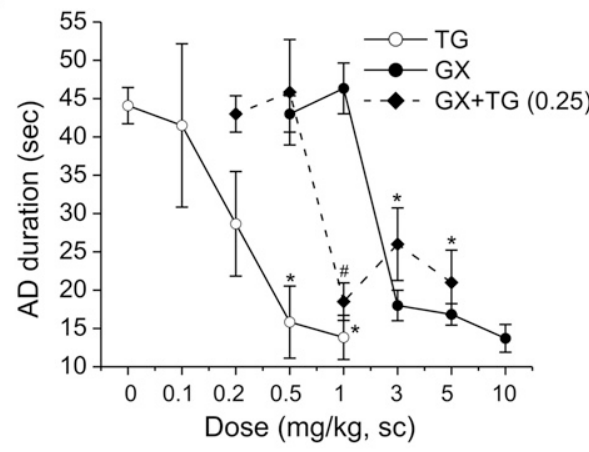

$\mathbf{F}$

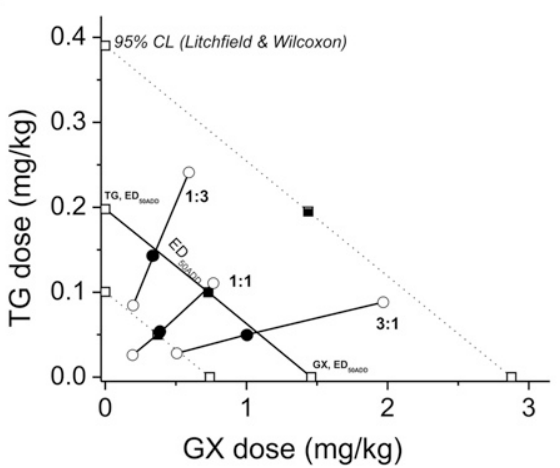

Fig. 4. Additive and synergistic anticonvulsant interactions between GX and TG in acute seizure models in mice. (A) The percentage of seizure protection by GX TG, or GX + TG. GX and TG reduced seizures in a dose-dependent fashion in the $6-\mathrm{Hz}$ model. Combination therapy of GX and TG $(0.25 \mathrm{mg} / \mathrm{kg})$ shifted the response curve of GX toward the left, indicating possible synergism. (B) Efficacy timeline for GX $(5 \mathrm{mg} / \mathrm{kg})$ and TG $(0.25 \mathrm{mg} / \mathrm{kg})$ in the $6-\mathrm{Hz}$ model. GX displayed significantly faster peak response time than TG, with similar rates of decay for each. GX and TG reduced the seizure stage $(C)$ and $A D$ duration (D) in a dose-dependent fashion in fully kindled mice. Combination therapy of GX and TG $(0.25 \mathrm{mg} / \mathrm{kg})$ shifted the doseresponse curves toward the left, indicating possible synergism. (E) Log-probit doseresponse relationship lines for GX and TG administered alone in the $6-\mathrm{Hz}$-induced partial seizure model. (F) Isobologram showing interactions between GX and TG in the $6-\mathrm{Hz}$ seizure model. The dosing for GX is plotted graphically on the $x$-axis, and the dosing for TG is plotted graphically on the $y$-axis. The straight line represents the theoretical line of additivity for a continuum of different fixed concentration ratios, whereas the dashed lines represent the theoretical additive $95 \% \mathrm{CLs}$ of $\mathrm{ED}_{50}$ values. $\mathrm{ED}_{50}$ denotes the dose needed to achieve seizure protection in $50 \%$ of animals. The experimental $\mathrm{ED}_{50}$ values of the mixture of GX + TG for fixed ratios fall at or below the theoretical line of additivity. $* P<0.05$ vs. control; \#P<0.05 vs. GX ( $n=6-10$ per group). Behavioral seizure data were analyzed by the nonparametric Kruskal-Wallis test followed by the Mann-Whitney $U$ test. preclinical studies (Tallarida, 2006; Wojda et al., 2009). We first examined the $\mathrm{EF}_{\text {twofold }}$ values that represent the effective functional concentration of drug (nanomolars) required to double the endogenous basal tonic response in DGGCs (Fig. 2, D-F). According to the concentration-response curves of GX and TG, we deduced the $\mathrm{EF}_{\text {twofold }}$ values of GX and TG as $250 \mathrm{nM}$ and $220 \mathrm{nM}$, respectively (Fig. 2, D and F). Commonly used fixed-ratio drug combinations at 1:3, 1:1, and 3:1 were tested in DGGCs to quantify the contribution of each drug to the overall effects. Theoretically, if their interactions are purely additive, half of the $\mathrm{EF}_{\text {twofold }}$ value of a first drug plus half of the $\mathrm{EF}_{\text {twofold }}$ value of a second drug should exert 2 -fold potentiation of the basal tonic response as a full $\mathrm{EF}_{\text {twofold }}$ concentration of each drug administered separately. The theoretical $\mathrm{EF}_{\text {twofold }}\left(\mathrm{EF}_{\text {twofold add }}\right)$ values for mixtures of $\mathrm{GX}$ and TG at three fixed ratios (1:3, 1:1, and 3:1) are shown in Table 2. The experimental $\mathrm{EF}_{\text {twofold }}\left(\mathrm{EF}_{\text {twofold mix }}\right)$ values were derived from the tonic current modulation of each mixture. The tonic current shift ( $\mathrm{pA}$ ) and current density ( $\mathrm{pA}$ per $\mathrm{pF}$ ) exerted by each mixture of drug combinations are shown in Table 1. The isobologram was plotted, and the theoretical and experimental $\mathrm{EF}_{\text {twofold }}$ of mixtures were compared (Fig. 3;

TABLE 3

Isobolographic analysis showing theoretical $\left(\mathrm{EF}_{50 \text { add }}\right)$ and experimentally determined $\left(\mathrm{EF}_{50 \text { mix }}\right)$ values of $\mathrm{GX}$ and $\mathrm{TG}$ combinations against the 6 -Hz-induced seizures

\begin{tabular}{|c|c|c|c|c|c|c|c|c|c|}
\hline \multirow{2}{*}{$\begin{array}{l}\text { AED Combination } \\
\text { GX + TG }\end{array}$} & \multirow{2}{*}{$\begin{array}{c}\text { Fixed Ratio } \\
1: 3\end{array}$} & \multicolumn{3}{|c|}{$\mathrm{GX}+\mathrm{TG}=\mathrm{ED}_{50 \mathrm{mix}}(\mathrm{mg} / \mathrm{kg})$} & \multirow{2}{*}{$\begin{array}{c}n_{\text {mix }} \\
32\end{array}$} & \multicolumn{3}{|c|}{$\mathrm{EF}_{50 \text { add }}=\mathrm{GX}+\mathrm{TG}(\mathrm{mg} / \mathrm{kg})$} & \multirow{2}{*}{$\begin{array}{c}n_{\text {add }} \\
32\end{array}$} \\
\hline & & 0.341 & 0.143 & $0.484(0.282-0.833)$ & & $0.514(0.26-1.012)$ & 0.365 & 0.149 & \\
\hline $\mathrm{GX}+\mathrm{TG}$ & $1: 1$ & 0.385 & 0.052 & $0.437(0.219-0.870)$ & 40 & $0.829(0.42-1.634)$ & 0.73 & 0.099 & 40 \\
\hline $\mathrm{GX}+\mathrm{TG}$ & $3: 1$ & 0.999 & 0.05 & $1.049(0.535-2.057)$ & 32 & $1.145(0.58-2.255)$ & 1.095 & 0.050 & 32 \\
\hline
\end{tabular}

$n_{\text {add }}$, total animal numbers used to calculate the theoretical line of additivity; $n_{\text {mix }}$, total animal numbers in each mixture of drug combinations. 
TABLE 4

CI of the combinations of GX and TG in the antiseizure activity

\begin{tabular}{lllll}
\hline $\mathrm{ED}_{50}$ & \multicolumn{1}{c}{ GX } & \multicolumn{1}{c}{ TG } & CI & \multicolumn{1}{c}{ Outcome } \\
\hline Alone & 1.46 & 0.198 & & \\
$\mathrm{GX}+\mathrm{TG}=1: 3$ & 0.341 & 0.143 & 0.96 & Additivity/synergy \\
$\mathrm{GX}+\mathrm{TG}=1: 1$ & 0.385 & 0.052 & 0.53 & Synergy \\
$\mathrm{GX}+\mathrm{TG}=3: 1$ & 0.999 & 0.05 & 0.94 & Additivity/synergy \\
\hline
\end{tabular}

Table 2). In the isobologram, the $\mathrm{EF}_{\text {twofold }}$ for $\mathrm{GX}(250 \mathrm{nM})$ is plotted graphically on the $x$-axis, whereas the $\mathrm{EF}_{\text {twofold }}$ for TG $(220 \mathrm{nM})$ is plotted graphically on the $y$-axis. The distances between open-square points on the $x$ - and $y$-axes represent the $95 \% \mathrm{CLs}$ for the drugs treated alone. The straight line connecting these two $\mathrm{EF}_{\text {twofold }}$ values on the graph represents the theoretical line of additivity for a continuum of different fixed concentration ratios, whereas the dashed lines represent the theoretical additive $95 \% \mathrm{CLs}$ of $\mathrm{EF}_{\text {twofold }}$ values. All three combination regimens of GX and TG were located below the additivity line (Fig. 3B), indicating their synergistic interactions.

Log-Probit Dose-Response Analysis of Anticonvulsant Effects of GX and TG. In seizure protection studies, GX and TG administered alone reduced seizures in a dosedependent fashion in both $6-\mathrm{Hz}$ and kindling seizure model in mice (Fig. 4, A, C, and D). GX displayed a significantly faster peak response time than $\mathrm{TG}$, with similar rates of disposition for each (Fig. 4B). Administration of GX with TG at $0.25 \mathrm{mg} / \mathrm{kg}$ caused a leftward shift of GX dose response in the 6-Hz model (Fig. 4A); a similar protection trend of reduced seizure stage and $\mathrm{AD}$ duration was noted in the kindling model, suggesting additive/synergistic effects of GX + TG combination in mouse seizure models (Fig. 4, C and D). To study the interactions of GX with TG on seizure protection, a mouse $6-\mathrm{Hz}$ model of epilepsy was used. First, we determined the $\mathrm{ED}_{50}$ of each drug by using log-probit linear regression analysis (Litchfield and Wilcoxon, 1949). GX was given at increasing doses $(0.5-10 \mathrm{mg} / \mathrm{kg})$, and the percent protection against 6-Hz-induced seizures was calculated. The dose-response relationship for GX administered alone was determined as $\mathrm{y}=5.30092 \mathrm{x}+5.30092\left[r^{2}=0.92463\right]$, where $y$ denotes probit of response, $\mathrm{x}$ denotes logarithm of the drug dose 10, and $r^{2}$ denotes coefficient of determination (Fig. $4 \mathrm{E}$ ). The $\mathrm{ED}_{50}$ value for $\mathrm{GX}$ was 1.46 (95\% CL, $0.74-2.88) \mathrm{mg} / \mathrm{kg}$. Similarly, TG was administered at various doses $(0.1-1 \mathrm{mg} / \mathrm{kg})$, and the percent protection exerted by these doses was calculated. The dose-response relationship for TG was $\mathrm{y}=4.71065 \mathrm{x}+3.03345\left[r^{2}=0.95594\right]$. The $\mathrm{ED}_{50}$ value for TG was $0.20(95 \% \mathrm{CL}, 0.10-0.39) \mathrm{mg} / \mathrm{kg}$. The $\chi^{2}$ analysis revealed that the points creating the log-probit doseresponse relationship lines for GX and TG were not heterogeneous and thus good to fit because the experimentally denoted $\chi^{2}$ values $(\mathrm{GX}=2.370 ; \mathrm{TG}=1.193)$ were lower than the tabular $\chi^{2}$ values $(\mathrm{GX}=7.815$; $\mathrm{TG}=5.991)$. The parallelism test for two log-probit dose-response curves showed that the slope function ratio was lower than the factor for the slope function ratio, confirming that the lines are parallel to one another.

Synergistic Anticonvulsant Effects of GX and TG Combinations in the 6-Hz Seizure Model. In the isobolographic analysis, the theoretical $\mathrm{ED}_{50}$ add values for a mixture of GX and TG at three fixed ratios (1:3, 1:1, and 3:1) were calculated as (in milligrams per kilogram) 0.514 (95\% CL, $0.260-1.012), 0.829$ (95\% CL, $0.420-1.634)$, and 1.145 (95\% CL, 0.580-2.255), respectively (Fig. 4; Table 3). The experimental $\mathrm{ED}_{50 \text { mix }}$ values were derived from the seizure protection exerted by each mixture at $1: 3,1: 1$, and $3: 1$ as 0.484 (0.282-0.833), 0.437 (0.219-0.870), and 1.049 (0.535-2.057), respectively. The mixture of GX and TG at the fixed ratio of $1: 1$ exerted the greatest synergism $(\mathrm{CI}=0.53$; Table 4$)$, whereas CIs for the mixture of GX and TG at 3:1 and 1:3 combinations
A

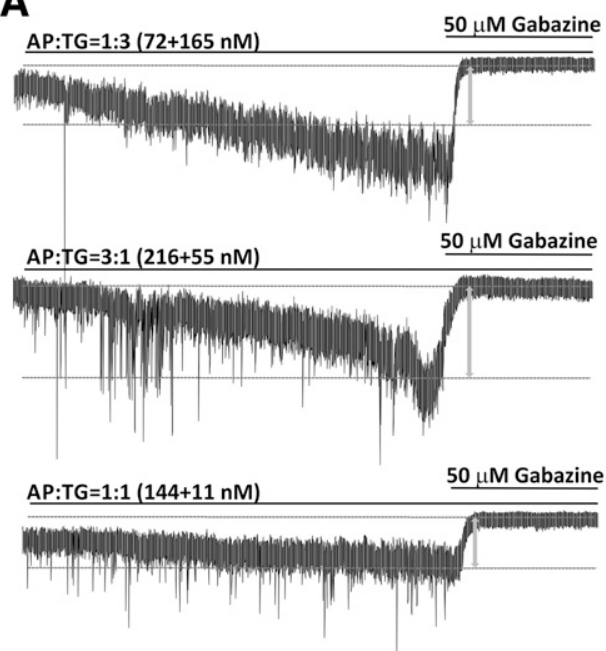

B

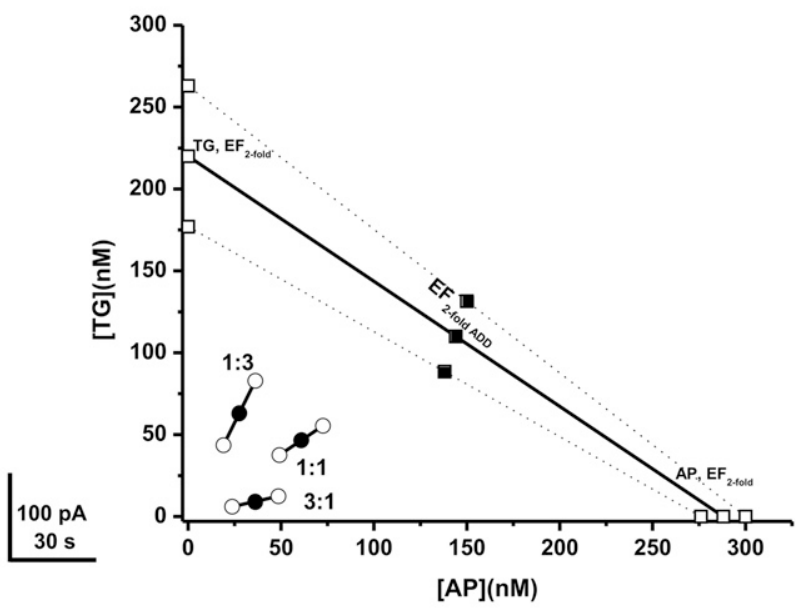

Fig. 5. Synergistic interactions between $\mathrm{AP}$ and $\mathrm{TG}$ of all combinations tested in the tonic current potentiation. (A) Representative whole-cell recordings of tonic currents in DGGCs in response to combinations of AP and TG. (B) Isobologram showing interactions between AP and TG in tonic current potentiation in DGGCs. The $\mathrm{EF}_{2}$ for $\mathrm{AP}(288 \mathrm{nM})$ is plotted graphically on the $x$-axis, whereas the $\mathrm{EF}_{2}$ for TG (220 nM) is plotted graphically on the $y$-axis. The distances between open-square points on the $x$ - and $y$-axes represent the 95\% CLs for the drugs treated alone. The straight line connecting these two $\mathrm{EF}_{2}$ values on the graph represents the theoretical line of additivity for a continuum of different fixed concentration ratios, whereas the dashed lines represent the theoretical additive $95 \% \mathrm{CLs}$ of $\mathrm{EF}_{2}$ values. $\mathrm{EF}_{2}$ denotes concentration needed to achieve 2-fold potentiation of endogenous basal tonic current $\left(10.8 \pm 1.6 \mathrm{pA} ; 0.31 \pm 0.06 \mathrm{pA} / \mathrm{pF}\right.$ ). The black circles depict the experimentally derived $\mathrm{EF}_{2}$ values (with $95 \%$ CLs as error bars) for the total concentration expressed as the proportion of $\mathrm{AP}$ and $\mathrm{TG}$ that produced 2-fold potentiation of basal tonic currents. The experimental $\mathrm{EF}_{2}$ values of the mixture of AP + TG in all three fixed ratios are placed below the theoretical line of additivity, indicating the tendency toward synergism. 
TABLE 5

Isobolographic analysis showing theoretical $\left(\mathrm{EF}_{\text {twofold add }}\right)$ and experimentally determined $\left(\mathrm{EF}_{\text {twofold mix }}\right)$ values of $\mathrm{AP}$ and $\mathrm{TG}$ combinations on tonic current potentiation in DGGCs

\begin{tabular}{lcccrcrrr}
\hline AED Combination & Fixed Ratio & \multicolumn{2}{c}{$\mathrm{AP}+\mathrm{TG}=\mathrm{EF}_{\text {twofold mix }}(\mathrm{nM})$} & \multicolumn{2}{c}{$n_{\text {mix }}$} & \multicolumn{2}{c}{$\mathrm{EF}_{\text {twofold add }}=\mathrm{AP}+\mathrm{TG}(\mathrm{nM})$} \\
\hline $\mathrm{AP}+\mathrm{TG}$ & $1: 3$ & 27.6 & 63.2 & $90.8 \pm 28.2$ & 6 & $237 \pm 35.3$ & 72 & 165 \\
$\mathrm{AP}+\mathrm{TG}$ & $1: 1$ & 60.8 & 46.5 & $107.3 \pm 20.6$ & 6 & $254 \pm 27.5$ & 144 & 110 \\
$\mathrm{AP}+\mathrm{TG}$ & $3: 1$ & 36.1 & 9.2 & $45.3 \pm 15.6$ & 6 & $271 \pm 19.8$ & 216 & 55 \\
\hline
\end{tabular}

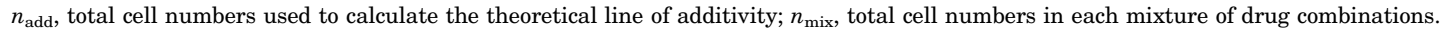

were 0.94 and 0.96 , respectively. In addition, combinations tested between GX and TG at 1:3 and 3:1 are plotted in the theoretical line of additivity, whereas the combination at 1:1 was plotted below the additive line in the isobologram (Fig. 4F), indicating synergistic (supra-additive) interaction.

Synergistic Potentiating Effects of AP and TG Coapplication on Tonic Currents in Hippocampal DGGCs. To further characterize the combination interactions between neurosteroids and TG on tonic currents, we also examined the interactions of the endogenous neurosteroid AP and TG by using isobolographic analysis (Fig. 5). The $\mathrm{EF}_{\text {twofold }}$ value of AP was $290 \mathrm{nM}$ (Fig. 2E). Fixed-ratio drug combinations at 1:3,1:1, and 3:1 were examined in DGGCs to quantify the contribution of each drug to the overall effects. The theoretical $\mathrm{EF}_{\text {twofold }}\left(\mathrm{EF}_{\text {twofold add }}\right)$ values for mixtures of $\mathrm{AP}$ and $\mathrm{TG}$ at three fixed ratios (1:3, 1:1, and 3:1) were shown in Table 5. The experimental $\mathrm{EF}_{\text {twofold }}\left(\mathrm{EF}_{\text {twofold mix }}\right)$ values were derived from the tonic current modulation of each mixture. In the isobologram, the $\mathrm{EF}_{\text {twofold }}$ for $\mathrm{AP}(288 \mathrm{nM})$ is plotted graphically on the $x$-axis, whereas the $\mathrm{EF}_{\text {twofold }}$ for TG $(220 \mathrm{nM})$ is plotted graphically on the $y$-axis. The plots of test combinations of AP and TG appeared below the additive line (Fig. 5B), indicating a plausible synergistic interaction (Fig. 5).

Log-Probit Dose-Response Analysis of Anticonvulsant Effects of AP and TG. Next, we examined the interactions of $\mathrm{AP}$ and $\mathrm{TG}$ in the $6-\mathrm{Hz}$ seizure model. $\mathrm{AP}$ was given at the increasing doses of $1,3,5$, and $10 \mathrm{mg} / \mathrm{kg}$, and the percent protection against $6-\mathrm{Hz}$-induced partial seizures was $10,38.9$,
60 , and 99.7, respectively. The equation of dose-response relationship for AP administered alone was determined as $\mathrm{y}=9.28311 \mathrm{x}+1.69977\left[r^{2}=0.97008\right]$, where $\mathrm{y}$ denotes probit of response, $\mathrm{x}$ denotes logarithm of the drug dose 10, and $r^{2}$ denotes coefficient of determination (Fig. $6 \mathrm{~A}$ ). The $\mathrm{ED}_{50}$ value for AP was $4.20(2.7-5.8) \mathrm{mg} / \mathrm{kg}$. The equation for $\mathrm{TG}$ was $\mathrm{y}=$ $4.71065 \mathrm{x}+3.03345\left[r^{2}=0.95594\right]$, and the $\mathrm{ED}_{50}$ value for $\mathrm{TG}$ was $0.20(0.1-0.39) \mathrm{mg} / \mathrm{kg}$. The experimentally denoted $\chi^{2}$ values $(\mathrm{AP}=0.740 ; \mathrm{TG}=1.193)$ were lower than the tabular $\chi^{2}$ values $(\mathrm{AP}=7.815 ; \mathrm{TG}=5.991)$, signifying that the logprobit curves for AP and TG were not significantly heterogeneous and thus were good to fit.

Synergistic Anticonvulsant Effects of AP and TG Combinations in the 6-Hz Seizure Model. In the isobolographic analysis, the theoretical $\mathrm{ED}_{50}$ add values for mixtures of AP and TG at three fixed ratios (1:3, 1:1, and 3:1) were determined as (in milligrams per kilogram) 1.199 (0.75-1.74), 2.199 (1.4-3.1), and 3.2 (2.05-4.45), respectively (Fig. 5B; Table 6). The experimental $\mathrm{ED}_{50 \text { mix }}$ values were derived from the seizure-protective effects exerted by each mixture at $1: 3,1$ : 1 , and $3: 1$ as 2.464 (1.70-4.06), 0.835 (0.56-1.25), and 0.436 (0.24-0.79), respectively. All combinations tested between AP and TG showed strong synergistic interactions against 6$\mathrm{Hz}$-induced seizures because the $\mathrm{CI}$ of each mixture is less than $1(\mathrm{CI}=0.38,0.39$, and 0.79 at $1: 1,3: 1$, and $1: 3$ ratios, respectively, Table 7). All combination regimens of AP and TG at 1:3, 1:1, and 3:1 are all plotted below the additive line (Fig. 6B), indicating synergistic anticonvulsant interactions of AP and TG.
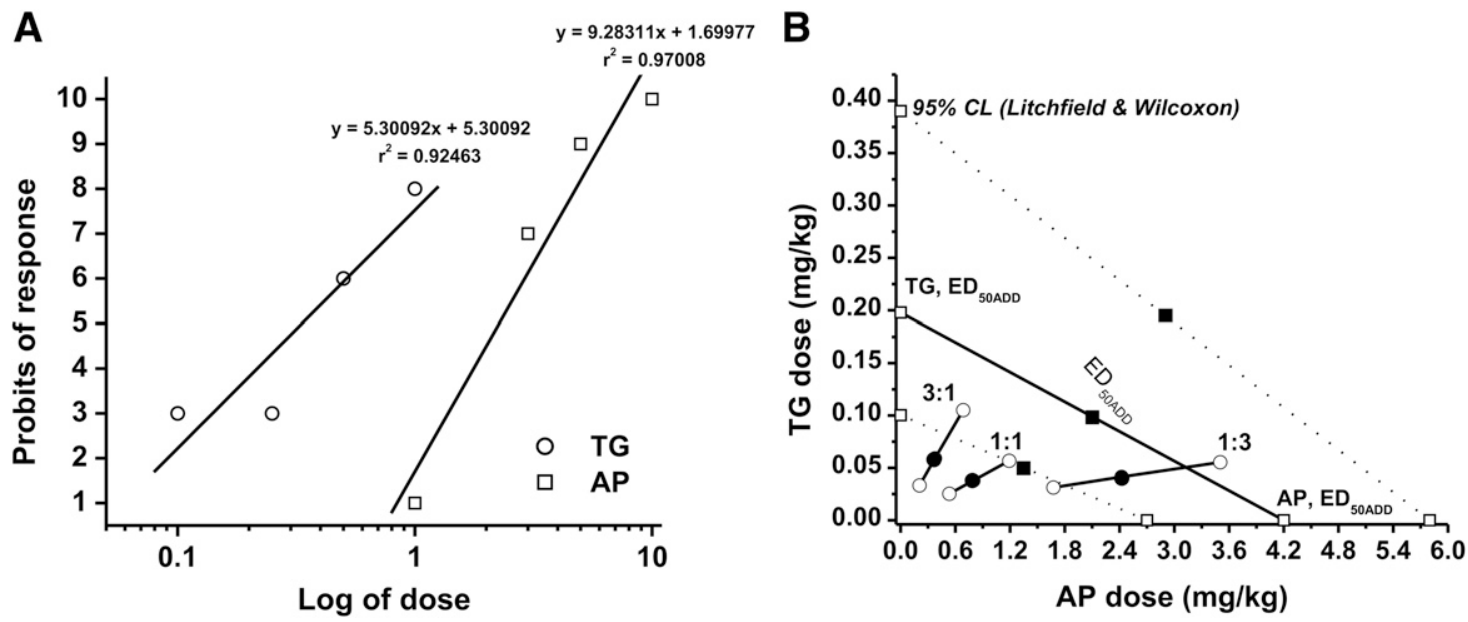

Fig. 6. Synergistic anticonvulsant interactions between AP and TG in the 6-Hz test in mice. (A) Log-probit dose-response relationship lines for AP and TG administered alone in the $6-\mathrm{Hz}$ partial seizure model. (B) Isobologram showing interactions between AP and TG in the 6-Hz seizure model. The dosing for AP is plotted graphically on the $x$-axis, and the dosing for TG is plotted graphically on the $y$-axis. The straight line represents the theoretical line of additivity for a continuum of different fixed concentration ratios, whereas the dashed lines represent the theoretical additive $95 \% \mathrm{CLs}_{\mathrm{s}}$ of $\mathrm{ED}_{50}$ values. $\mathrm{ED}_{50}$ denotes dose needed to achieve seizure protection in $50 \%$ of animals. The experimental $\mathrm{ED}_{50}$ values of the mixture of $\mathrm{AP}+\mathrm{TG}$ for fixed ratios fall at or below the theoretical line of additivity. 
TABLE 6

Isobolographic analysis showing theoretical $\left(\mathrm{EF}_{50}\right.$ add $)$ and experimentally determined $\left(\mathrm{EF}_{50 \text { mix }}\right)$ values of $\mathrm{AP}$ and $\mathrm{TG}$ combinations against 6-Hz-induced seizures

\begin{tabular}{|c|c|c|c|c|c|c|c|c|c|}
\hline \multirow{2}{*}{$\begin{array}{l}\text { AED Combination } \\
\mathrm{AP}+\mathrm{TG}\end{array}$} & \multirow{2}{*}{$\begin{array}{c}\text { Fixed Ratio } \\
1: 3\end{array}$} & \multicolumn{3}{|c|}{$\mathrm{AP}+\mathrm{TG}=\mathrm{ED}_{50 \text { mix }}(\mathrm{mg} / \mathrm{kg})$} & \multirow{2}{*}{$\begin{array}{c}n_{\text {mix }} \\
32\end{array}$} & \multicolumn{3}{|c|}{$\mathrm{EF}_{50 \text { add }}=\mathrm{AP}+\mathrm{TG}(\mathrm{mg} / \mathrm{kg})$} & \multirow{2}{*}{$\begin{array}{c}n_{\text {add }} \\
32\end{array}$} \\
\hline & & 2.422 & 0.042 & $2.464(1.705-4.058)$ & & $1.199(0.75-1.74)$ & 1.05 & 0.149 & \\
\hline $\mathrm{AP}+\mathrm{TG}$ & $1: 1$ & 0.797 & 0.038 & $0.835(0.559-1.247)$ & 32 & $2.199(1.40-3.10)$ & 2.1 & 0.099 & 32 \\
\hline $\mathrm{AP}+\mathrm{TG}$ & $3: 1$ & 0.377 & 0.059 & $0.436(0.24-0.791)$ & 32 & $3.200(2.05-4.45)$ & 3.15 & 0.050 & 32 \\
\hline
\end{tabular}

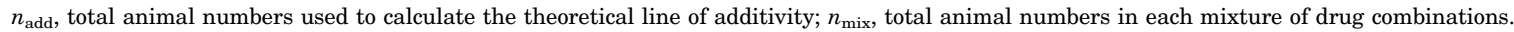

Combination Efficacy of GX and MDZ on Tonic Current Potentiation in Hippocampal DGGCs. The benzodiazepine MDZ is an allosteric agonist of synaptic GABA-A receptors through sites distinct from the neurosteroid binding site (Nusser et al., 1997). Therefore, it is plausible that neurosteroid + MDZ exerts a synergistic response on GABA-A receptor function through a mechanism involving distinct sites and thereby may be more effective for refractory seizures; however, this has not been widely investigated in seizure models. Here, we tested whether coapplication of neurosteroids with MDZ elicits additive or synergistic effects on tonic inhibition in hippocampal DGGCs (Fig. 7). Like GX + TG coapplication experiments, we have simulated isobolograms for two allosteric drugs (GX and MDZ) combined. The results (Fig. 7D) demonstrate that coapplication of GX and MDZ produces a curvilinear isobole; however, the curvature is less pronounced because of limited efficacy of MDZ at extrasynaptic receptors (Fig. 7D). Nevertheless, combinations of GX and MDZ at three fixed ratios exerted synergistic potentiation of tonic currents as they are plotted below the theoretical line in the isobologram (Fig. 7D; Table 8). These results are highly consistent with those from a recent study on the potentiating effect of alfaxolone, which showed that the addition of a second GABAergic drug, diazepam, leads to a greater effect because of their distinct binding sites on the GABA-A receptors (Shin et al., 2019).

Anticonvulsant Activity of GX and MDZ Combination Regimens in the 6-Hz Seizure Model. In the 6-Hz seizure model, MDZ was given at increasing doses $(0.05-3 \mathrm{mg} / \mathrm{kg})$, and the percent protection was derived from the analysis. The dose-response relationship for MDZ administered alone was determined as $\mathrm{y}=4.69735 \mathrm{x}+6.90629\left[r^{2}=0.92273\right]$, where y denotes probit of response, $\mathrm{x}$ denotes logarithm of the drug dose 10, and $r^{2}$ denotes coefficient of determination (Fig. 8A). The $\mathrm{ED}_{50}$ value for $\mathrm{MDZ}$ was $0.40(0.11-0.69) \mathrm{mg} / \mathrm{kg}$. The equation for GX was $\mathrm{y}=5.30092 \mathrm{x}+5.30092\left[r^{2}=0.92463\right]$, and the $\mathrm{ED}_{50}$ value for $\mathrm{GX}$ was $1.46(0.74-2.88) \mathrm{mg} / \mathrm{kg}$. The experimentally denoted $\chi^{2}$ values $(\mathrm{GX}=2.370 ; \mathrm{MDZ}=10.118)$ were lower than the tabular $\chi^{2}$ values $(\mathrm{GX}=7.815 ; \mathrm{MDZ}=$ 11.07), signifying that the log-probit dose-response relationship lines for GX and MDZ were not significantly heterogeneous and thus were good to fit. In the isobolographic analysis, the theoretical $\mathrm{ED}_{50}$ add values for mixtures of $\mathrm{GX}$ and $\mathrm{MDZ}$ at

TABLE 7

CI of the combinations of AP and TG in the antiseizure activity

\begin{tabular}{llccl}
\hline ED50 & AP & TG & CI & \\
\hline Alone & 4.2 & 0.198 & & \\
AP + TG $=1: 3$ & 2.422 & 0.042 & 0.79 & Synergy \\
AP + TG $=1: 1$ & 0.797 & 0.038 & 0.38 & Synergy \\
AP + TG $=3: 1$ & 0.377 & 0.059 & 0.39 & Synergy \\
\hline
\end{tabular}

three fixed ratios $(1: 3,1: 1$, and $3: 1)$ were determined as (in milligrams per kilogram) 0.665 (0.268-1.237), 0.930 (0.624-1.784), and 1.195 (0.538-2.330), respectively (Fig. 8B; Table 9). The experimental $\mathrm{ED}_{50 \text { mix }}$ values were derived from the seizureprotective effects exerted by each mixture at $1: 3,1: 1$, and $3: 1$ as $0.910(0.608-0.364), 0.550(0.368-0.823)$, and 0.404 (0.259-0.631), respectively. All combinations tested between GX and MDZ showed strong synergistic interactions for seizure protection because CIs of each mixture are less than 1 (CI $=0.76$, 0.59 , and 0.61 at 1:1, 3:1, and 1:3 ratios, respectively, Table 10). In addition, combinations tested between GX and MDZ at 1:3, 1:1, and 3:1 are all plotted below the additive line (Fig. 8B), indicating synergistic anticonvulsant interactions between GX and MDZ in the 6-Hz seizure model.

\section{Discussion}

The main finding of the present study is the demonstration of synergistic effects of neurosteroids and TG combinations in potentiating tonic inhibition in the hippocampus slices and protecting against acute seizures. This synergistic effect is likely due to a greater potentiation at extrasynaptic $\delta \mathrm{GABA}-\mathrm{A}$ receptors by neurosteroids through TG-induced elevated levels of extracellular GABA. The potential pharmacodynamic synergistic interaction between neurosteroids and the benzodiazepine MDZ provides better protection against acute seizures (Fig. 9). Together, these findings provide a pharmacological basis for synergistic therapeutic potential of neurosteroids with TG or MDZ for epilepsy therapy, with reduced doses and possibly reduced side effects.

Neurosteroids can interact with other GABAergic drugs within the receptor milieu or at the receptor complex (Fig. 9). The molecular mechanisms of action of neurosteroids on the GABA neurotransmitter system include allosteric and direct agonism on GABA-A receptors (Hosie et al., 2007). GX and AP potentiate phasic and tonic currents by acting at synaptic and extrasynaptic $\delta$-rich receptors in DGGCs, respectively. GX and AP exhibit comparable allosteric and direct effects on GABAgated chloride currents (Chuang and Reddy, 2018b, 2019). TG is a selective GABA transporter-1 inhibitor that blocks the reuptake of GABA into neurons and glial cells, resulting in the elevation of GABA concentration in the synaptic cleft and extracellular milieu (Czuczwar and Przesmycki, 2001). Therefore, it is predictable that combination treatment of TG and neurosteroids (AP or GX) exerts synergistic effects on extrasynaptic GABA-A receptor-mediated tonic inhibition in dentate gyrus because the allosteric potentiating actions of neurosteroid on GABA-A receptors were GABA dependent. However, the relationship between the extent of extrasynaptic GABA-A receptor-mediated tonic inhibition within various circuits versus in vivo seizure protection after TG-neurosteroid combination is mechanistically complex. 
A
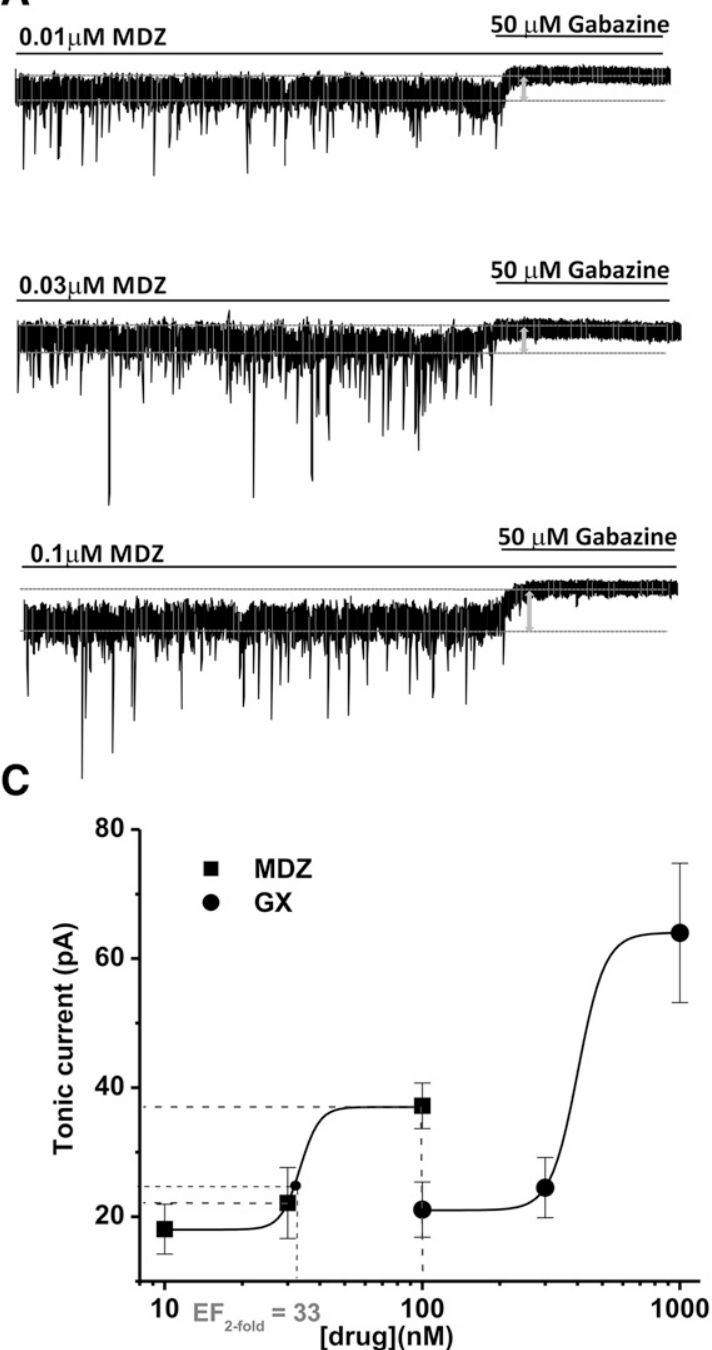

B
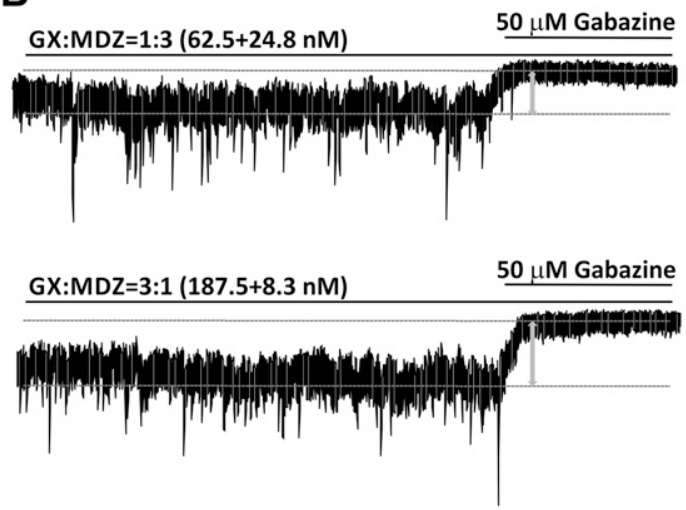

GX:MDZ=1:1 (125+16.5 nM) $\quad 50 \mu \mathrm{M}$ Gabazine

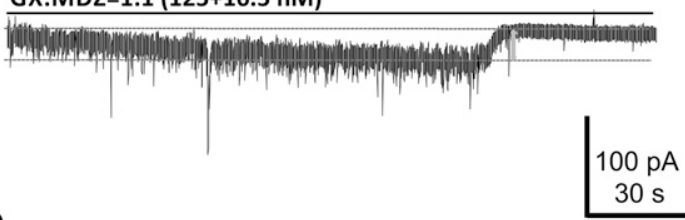

D

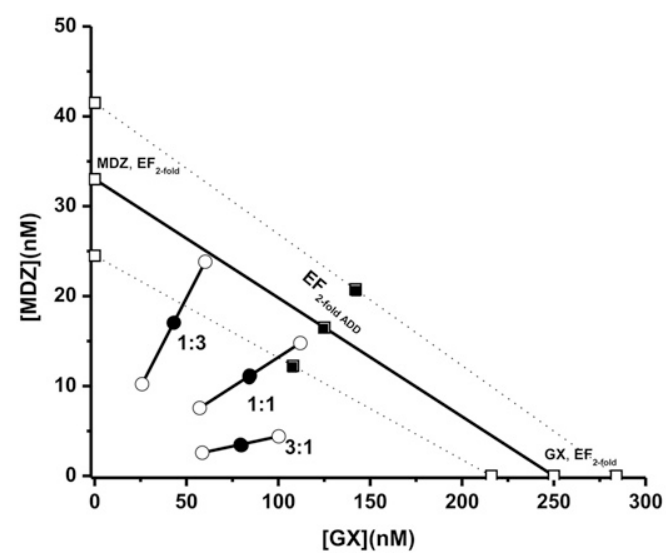

Fig. 7. Synergistic interactions between GX and MDZ in the tonic current potentiation. (A) Representative whole-cell recordings of tonic currents in DGGCs in response to MDZ $(0.01-0.1 \mu \mathrm{M})$. (B) Representative whole-cell recordings of tonic currents in DGGCs in response to combinations of GX and MDZ. (C) Concentration-response curves of GX and MDZ alone in the potentiation of tonic currents (pA). (D) Isobologram showing interactions between GX and MDZ in tonic current potentiation in DGGCs. The $\mathrm{EF}_{2}$ for GX $(250 \mathrm{nM})$ is plotted graphically on the $x$-axis, whereas the $\mathrm{EF}_{2}$ for $\mathrm{MDZ}$ (33 $\mathrm{nM}$ ) is plotted graphically on the $y$-axis. The distances between open-square points on the $x$ - and $y$-axes represent the 95\% CLs for the drugs treated alone. The straight line connecting these two $\mathrm{EF}_{\text {twofold }}$ values on the graph represents the theoretical line of additivity for a continuum of different fixed concentration ratios, whereas the dashed lines represent the theoretical additive $95 \% \mathrm{CLs}$ of $\mathrm{EF}_{2}$ values. $\mathrm{EF}_{2}$ denotes the concentration needed to achieve 2 -fold potentiation of endogenous basal tonic current $(10.8 \pm 1.6 \mathrm{pA} ; 0.31 \pm 0.06 \mathrm{pA} / \mathrm{pF})$. The black circles depict the experimentally derived EF 2 values (with 95\% CLs as error bars) for the total concentration expressed as the proportion of GX and MDZ that produced 2-fold potentiation of basal tonic currents. The experimental $\mathrm{EF}_{2}$ values of the mixture of $\mathrm{GX}+\mathrm{MDZ}$ for the entire fixed ratio fall at or below the theoretical line of additivity, indicating the tendency toward additivity.

In contrast to direct application of test drugs in the brain slice studies, systemic administration of drug combinations immerses the entire brain, which affects various brain regions and circuits, causing widespread effects. TG blockade of GABA uptake on the GABAergic terminals and glial cells may have effects on both glutamatergic cells and a range of different GABA neurons, with distinct projections to different circuits (Patel et al., 2015). Nevertheless, it is likely that the in vivo seizure protection outcomes may reflect the net circuit consideration in the underlying synergistic interaction between TG and neurosteroids.

This study was conducted in male mice to limit the complexity of ovarian hormone influences on neurosteroid actions in females (Wu et al., 2013; Reddy et al., 2019). In the future, we will consider replicating these studies in female cohorts. In addition, the recording temperature can affect drug interactions at GABA-A receptors in brain slices (Jenkins et al., 1999). In this study, the slices were incubated at $28^{\circ} \mathrm{C}$, and recordings were made at room temperature, as described previously (Carver and Reddy, 2016). Although such condition has little impact on neurosteroids (nonvolatile lipophilic molecules), the overall outcomes of the current study are still valid for assessing the neurosteroid combination regimens tested under similar conditions. Test drugs enhanced the miniature inhibitory postsynaptic currents (mIPSCs) in brain slice studies. These currents were potentiated 1- to 2-fold by TG and GX (Fig. 2), except for AP (brexanolone), which elicited strikingly greater potentiation of 3- to 4-fold increases in amplitude from the control level (Fig. 2, B and C). We attribute this effect to its high efficacy at extrasynaptic 
TABLE 8

Isobolographic analysis showing theoretical $\left(\mathrm{EF}_{\text {twofold add }}\right)$ and experimentally determined $\left(\mathrm{EF}_{\text {twofold mix }}\right)$ values of GX and $\mathrm{MDZ}$ combinations on tonic potentiation in DGGCs

\begin{tabular}{lcccccccc}
\hline AED Combination & Fixed Ratio & \multicolumn{2}{c}{$\mathrm{GX}+\mathrm{MDZ}=\mathrm{EF}_{\text {twofold mix }}(\mathrm{nM})$} & $\mathrm{n}_{\text {mix }}$ & \multicolumn{2}{c}{$\mathrm{EF}_{\text {twofold add }}=\mathrm{GX}+\mathrm{MDZ}(\mathrm{nM})$} & $\mathrm{n}_{\text {add }}$ \\
\hline $\mathrm{GX}+\mathrm{MDZ}$ & $1: 3$ & 43.0 & 17.0 & $60.0 \pm 24.0$ & 6 & $87.3 \pm 14.9$ & 62.5 & 24.8 \\
$\mathrm{GX}+\mathrm{MDZ}$ & $1: 1$ & 84.6 & 11.2 & $95.8 \pm 31.0$ & 6 & $141.5 \pm 21.3$ & 125 & 16.5 \\
$\mathrm{GX}+\mathrm{MDZ}$ & $3: 1$ & 79.4 & 3.5 & $82.9 \pm 21.7$ & 6 & $195.8 \pm 27.6$ & 187.5 & 8.3 \\
\hline
\end{tabular}

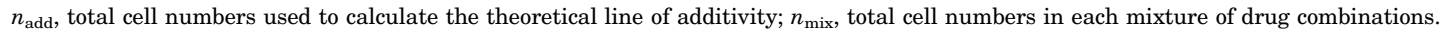

GABA-A receptors, which are highly sensitive to activation by certain neurosteroids (Carver and Reddy, 2016). The extent of the current is comparable to the data published earlier with other related neurosteroids (Chuang and Reddy, 2018b). This effect is consistent with neurosteroid effects recorded earlier on GABA-gated currents in whole-cell recordings, in which they elicited 3- to 5-fold greater potentiation of GABA-gated currents in dissociated granule cells or cultured neurons (Carter et al., 1997; Wu et al., 2013; Carver et al., 2014). Nevertheless, it is likely that AP can interact with other neurosteroid binding sites at higher levels (Chen et al., 2019).

Recently, Akk and colleagues proposed a concerted transition model to predict the interactions of drug combinations at GABA-A receptors (Akk et al., 2018). They used the $\mathrm{EC}_{50}$ for activation by GABA and basal activity of recombinant receptors in Xenopus oocytes. They found that the interactions of GABA with test drugs (propofol, pentobarbital, and alfaxolone) are additive and have no free energy changes detected, as predicted by their model. This model successfully predicts the drug interactions because their recombinant system is relatively simple and does not have any complicated neuronal circuits or connections, as in the slice recording. In addition, their results reflect the relationships between GABA and test drugs in GABA-gated currents recorded from constructed GABA-A receptors. In the present study, we examined tested combinations of GX and TG on extrasynaptic GABA-A receptor-mediated tonic currents from DGGCs in brain slices with intact circuits and network connections. We used the gold-standard isobolographic analysis to better assess their interactions. Our animal model results demonstrate synergistic effects of drug combinations in protecting against $6 \mathrm{~Hz}$-induced seizures. Despite such complex interactions, the major outcome of our study points to the clinical potential of a combination of neurosteroid with TG for better control of seizures.

The 6-Hz-induced partial seizure model is one of the most sensitive models for the evaluation of seizure-protective effects of AEDs that act on GABA system (Kaminski et al., 2004; Reddy et al., 2015). Neurosteroids and benzodiazepines exhibit powerful anticonvulsant activity in the $6-\mathrm{Hz}$ model. In the present study, our results show that both AP and GX have robust anticonvulsant effects in this model, providing support for that concept. Interestingly, in the combination studies, we found strong synergistic enhancement of anticonvulsant activity of AP when coadministered with TG. Both neurosteroids in combination with TG produced synergistic potentiation of tonic inhibition in the hippocampal dentate gyrus neurons. However, there are some striking differences between GX and AP. GX $\left(\mathrm{ED}_{50}=1.46 \mathrm{mg} / \mathrm{kg}\right)$ exhibits higher anticonvulsant potency than $\mathrm{AP}\left(\mathrm{ED}_{50}=4.20 \mathrm{mg} / \mathrm{kg}\right)$ in the $6-\mathrm{Hz}$ test. GX has greater bioavailability and fewer side effects than AP (Carter et al., 1997). Some pharmacodynamic differences may arise because of pharmacokinetic changes between GX and TG when administered simultaneously. Another possibility is the differences in the permeability of the drugs across the bloodbrain barrier. TG is a lipophilic agent that effectively and competitively inhibits the GABA transporter GAT-1 in the brain. TG has been used in the treatment of partial seizures as an add-on drug. However, its utility is limited because of its
A

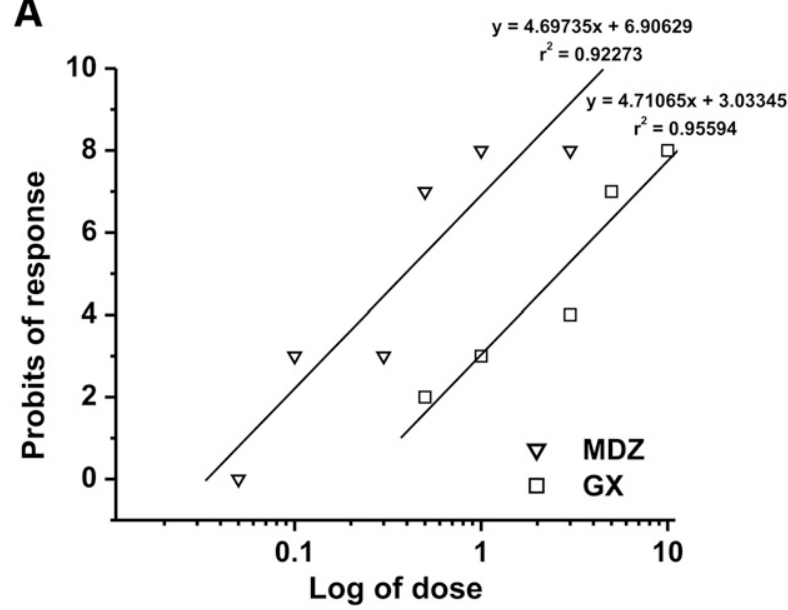

B

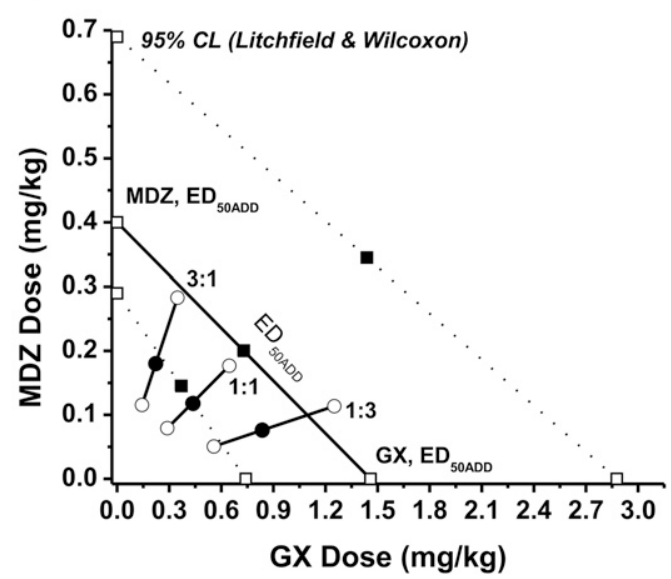

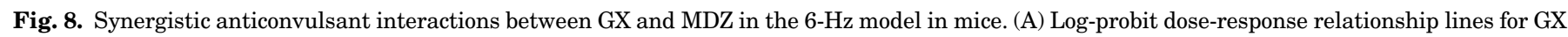

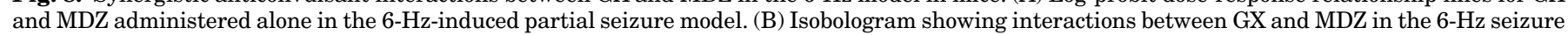

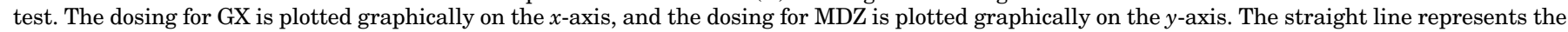

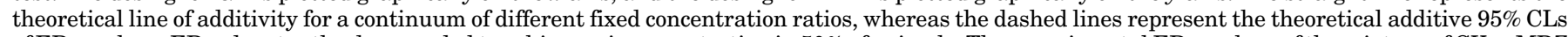

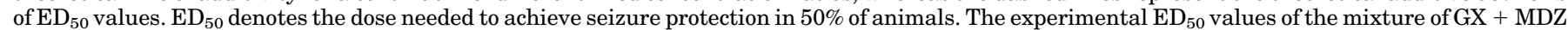
for fixed ratios fall at or below the theoretical line of additivity. 
TABLE 9

Isobolographic analysis showing theoretical $\left(\mathrm{EF}_{50 \text { add }}\right)$ and experimentally determined $\left(\mathrm{EF}_{50 \text { mix }}\right)$ values of GX and $\mathrm{MDZ}$ combinations against the 6-Hzinduced seizures

\begin{tabular}{|c|c|c|c|c|c|c|c|c|c|}
\hline AED Combination & Fixed Ratio & \multicolumn{3}{|c|}{$\mathrm{GX}+\mathrm{MDZ}=\mathrm{ED}_{50 \text { mix }}(\mathrm{mg} / \mathrm{kg})$} & $n_{\text {mix }}$ & \multicolumn{3}{|c|}{$\mathrm{EF}_{50 \text { add }}=\mathrm{GX}+\mathrm{MDZ}(\mathrm{mg} / \mathrm{kg})$} & $n_{\text {add }}$ \\
\hline $\mathrm{GX}+\mathrm{MDZ}$ & $1: 3$ & 0.834 & 0.076 & $0.910(0.608-0.364)$ & 32 & $0.665(0.268-1.237)$ & 0.365 & 0.3 & 32 \\
\hline GX + MDZ & $1: 1$ & 0.432 & 0.118 & $0.550(0.368-0.823)$ & 32 & $0.93(0.426-1.784)$ & 0.73 & 0.2 & 32 \\
\hline $\mathrm{GX}+\mathrm{MDZ}$ & $3: 1$ & 0.223 & 0.181 & $0.404(0.259-0.631)$ & 32 & $1.195(0.583-2.330)$ & 1.095 & 0.1 & 32 \\
\hline
\end{tabular}

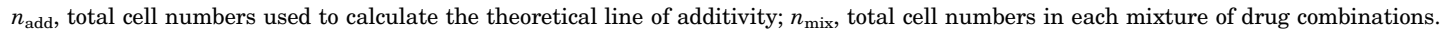

adverse profile and limited spectrum of seizure protection. Combined treatment of neurosteroids with TG largely reduces the dosages of each drug, providing better therapeutic outcomes. Some previous studies have shown the synergistic therapeutic potential of TG with other AEDs in other seizure models, including genetic epilepsy, supporting the benefits of combination therapies (Łuszczki and Czuczwar, 2004; Madsen et al., 2009; Oakley et al., 2013).

The benzodiazepine MDZ is widely used for controlling acute seizures and SE, but it is not highly effective for delayed therapy or refractory SE. MDZ is an allosteric agonist of synaptic GABA-A receptors through sites distinct from the neurosteroid binding site (Nusser et al., 1997). A previous study has shown that the combination of GX and MDZ exerts synergistic anxiolytic effects (Gunter et al., 2016). In the present study, we found that neurosteroid exerts a synergistic response with MDZ on GABA-A receptors. The interactions between neurosteroids and MDZ on GABA-A receptor function are complex, and several possible mechanisms could explain their synergistic effects on the antiepileptic activity. MDZ is a high-affinity, preferential, positive allosteric agonist of synaptic $\gamma$-containing GABA-A receptors that potentiates transient phasic inhibitory postsynaptic currents. Combined with low-affinity neurosteroids whose actions mainly lie on the potentiation of extrasynaptic $\delta$-containing GABA-A receptor-mediated tonic currents, the overall inhibitory GABA neurotransmitter system in the hippocampus is strongly enhanced and thus contributes to greater antiseizure activity. In addition, a recent study shows cross talk between phasic and tonic inhibition in DGGCs because $\delta$ GABA-A receptors also contribute to phasic inhibition that can effectively shunt excitatory postsynaptic potentials (Sun et al., 2018). MDZ also interacts with the steroid translocator protein TSPO, a translocator protein that plays a crucial role in the synthesis of neurosteroids (Papadopoulos et al., 2006). However, MDZ at therapeutic dosage does not influence the level of endogenous neurosteroid AP in plasma and brain (Reddy et al., 2015), indicating that such interaction is not related to changes in neurosteroid levels in the brain.

The precise mechanisms underlying the synergic protective response of neurosteroids are unknown. In general, the potential mechanisms underlying synergistic and additive effects on GABAergic tonic inhibition may result from a variety

TABLE 10

$\mathrm{CI}$ of the combinations of GX and MDZ in the antiseizure activity

\begin{tabular}{lllll}
\hline $\mathrm{ED}_{50}$ & $\mathrm{GX}$ & $\mathrm{MDZ}$ & $\mathrm{CI}$ & Outcome \\
\hline Alone & 1.46 & 0.4 & & \\
$\mathrm{GX}+\mathrm{MDZ}=1: 3$ & 0.834 & 0.076 & 0.76 & Synergy \\
$\mathrm{GX}+\mathrm{MDZ}=1: 1$ & 0.432 & 0.118 & 0.59 & Synergy \\
$\mathrm{GX}+\mathrm{MDZ}=3: 1$ & 0.223 & 0.181 & 0.61 & Synergy \\
\hline
\end{tabular}

of pharmacodynamic effects from a combination of two drugs, including both competitive and noncompetitive interactions at the receptor sites (Earp et al., 2004). The recent analysis of GABA-A receptor activation by combinations of agonists acting at the same or distinct binding sites has led to an interesting premise for predicting the efficacy of GABAergic drug mixtures in combination therapy (Shin et al., 2017, 2019; Cao et al., 2018). Coapplication of two GABAergic agents typically results in potentiation of the inhibitory current response. Direct activation of the GABA-A receptor and potentiation of GABA-gated receptors underlie the clinical actions of neurosteroids. The extent of current potentiation and, thereby, the in vivo anticonvulsant efficacy of a neurosteroid depend on the type of codrug. Combination of two agonists acting at the same sites can result in potentiation due to concentration additivity based on their individual efficacies and concentration (Shin et al., 2019). In contrast, GABAergic drug combinations in which the individual drugs interact with distinct sites may produce potentiation via energetic additivity, such as coapplication of propofol with GABA or coadministration of alfaxolone with diazepam (Cao et al., 2018). Coapplication of two allosteric agonists that interact with distinct sites would result in additivity of free energies for the open state of receptor channels (Shin et al., 2017). Thus, neurosteroid combination with MDZ that interacts with distinct sites may produce greater potentiation via energetic additivity and yield supra-additive or synergistic response, as evident from a curvilinear isobole (Fig. 8). It has been shown previously that coapplication of the synthetic neurosteroid alfaxolone enhances the GABAergic effects of etomidate ( $\mathrm{Li}$ et al., 2014) and diazepam (Cao et al., 2018). In the present study, we show that GX, which acts on the same sites as alfaxolone, exhibits synergism with MDZ on tonic current potentiation (Fig. 7). The indirect acting agents, such as TG, elevate the levels of GABA. Consequently, TG is predicted to be highly synergistic when combined with the neurosteroid $\mathrm{AP}$ (Fig. 5) or GX (Fig. 3) because they interact with distinct target sites. Such agonist combinations have significant clinical implications when combination therapies are desired for refractory epilepsy, pharmacoresistant SE, and other seizure disorders. High doses of currently used AEDs exhibit notable adverse effects and drug interactions. Neurosteroids provide viable adjuncts for combination therapy with AEDs for both increasing seizure control and reducing side effects associated with high doses of AEDs.

In conclusion, these results demonstrate marked synergistic effects of neurosteroid and TG combinations in protecting against acute seizures. This synergic antiseizure efficacy likely involves hippocampal extrasynaptic GABA-A receptors, which mediate tonic inhibition. It is also likely to involve various other neural circuits that are influenced by tonic inhibition. These findings provide a pharmacological basis 


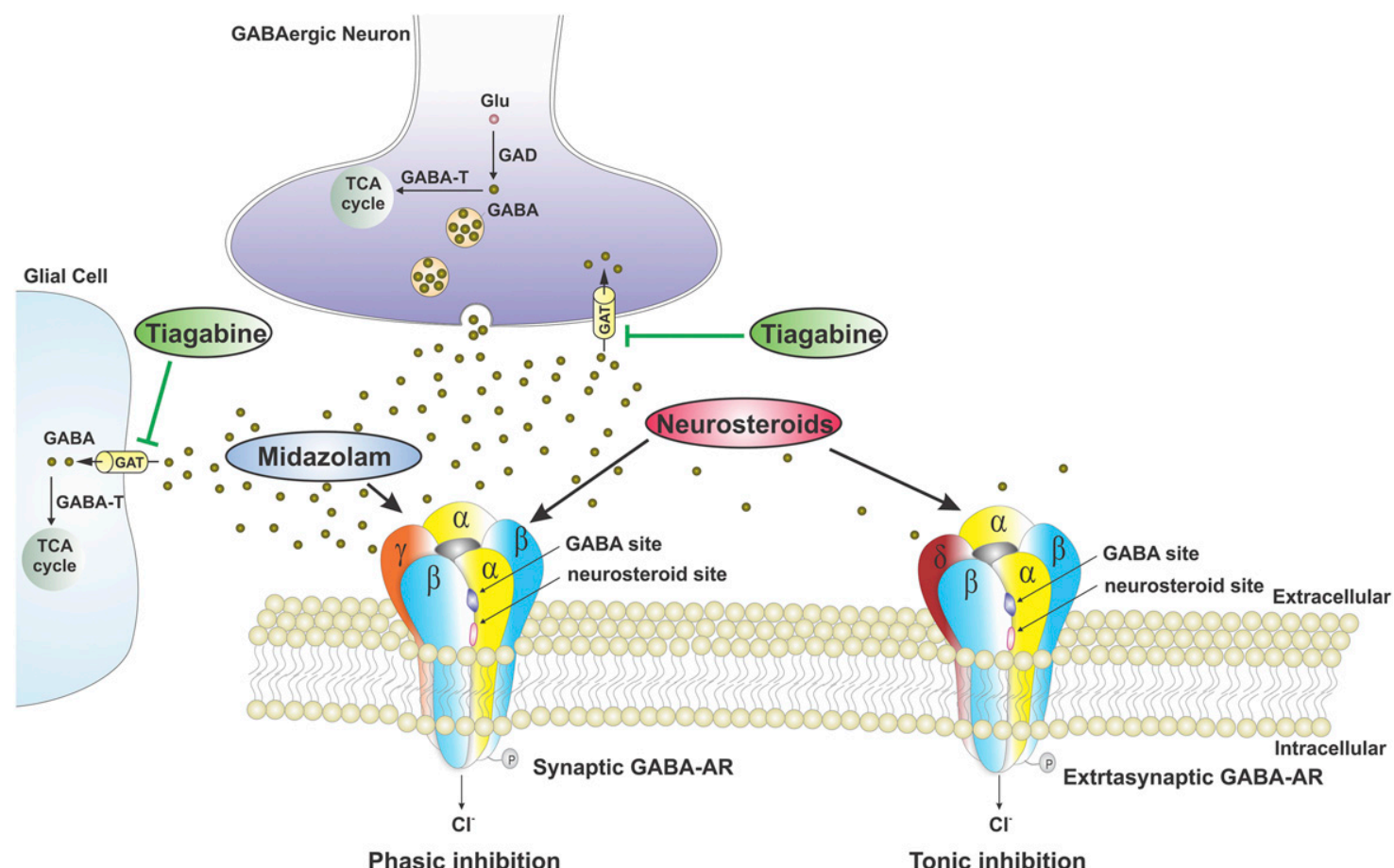

Fig. 9. An overview of potential molecular pathways of synergistic interactions between neurosteroids and the GABAergic drugs tiagabine (TG) or midazolam (MDZ). GABA-A receptors are pentameric GABA-gated chloride channels formed from 19 different subunits. Channels made from different combinations of subunits produce receptor subtypes with distinct functional properties. GABA-A receptors are classified into two major groups based on their location: synaptic and extrasynaptic receptors. Synaptic ( $\gamma$-containing) receptors generate transient inhibitory phasic current (phasic inhibition), whereas extrasynaptic ( $\delta$-containing) receptors generate a persistent inhibitory tonic current that regulates basal neuronal excitability (tonic inhibition). The GABA-reuptake inhibitor TG-induced elevation in GABA levels is suggested to augment the allosteric responses of neurosteroids at synaptic and extrasynaptic GABA-A receptors, possibly because of greater additivity of free energy for the open state of receptor channels. When the benzodiazepine MDZ is coadministered, a pharmacodynamic interaction is predicted to result in superadditive or synergism between neurosteroids and MDZ, possibly from energetic additivity as they interact with distinct sites on receptor complex. However, there is some limitation to this mechanistic model due to multiple circuit disruptions with the application of TG for blocking GABA update at multiple terminals. The underlying circuit-specific effects may complicate such simple correlation between the extent of tonic inhibition and in vivo seizure protection with drug combinations. GAT, GABA transporter; GABA-T, GABA transaminase; GAD, glutamate decarboxylase; Glu, Glutamate; TCA, tricarboxylic acid.

for clinical potential of neurosteroid-TG combination therapy for refractory epilepsy and other neuronal excitability conditions involving defects in tonic inhibition. Similarly, the synergism between GX and MDZ offers a viable path for their combination therapy for SE, such as the benzodiazepinerefractory SE following organophosphate and chemical nerve agent exposures.

\section{Acknowledgments}

The authors thank Hayden Anz and Bryan Clossen for their technical help with the $6-\mathrm{Hz}$ study.

\section{Authorship Contributions}

Participated in research design: Chuang, Reddy.

Conducted experiments: Chuang, Reddy.

Performed data analysis: Chuang, Reddy.

Wrote or contributed to the writing of the manuscript: Chuang, Reddy.

\section{References}

Adkins JC and Noble S (1998) Tiagabine. A review of its pharmacodynamic and pharmacokinetic properties and therapeutic potential in the management of epilepsy. Drugs 55:437-460.

Akk G, Shin DJ, Germann AL, and Steinbach JH (2018) GABA type A receptor activation in the allosteric coagonist model framework: relationship between $\mathrm{EC}_{50}$ and basal activity. Mol Pharmacol 93:90-100.

Belelli D and Lambert JJ (2005) Neurosteroids: endogenous regulators of the GABA(A) receptor. Nat Rev Neurosci 6:565-575.

Berenbaum MC (1977) Synergy, additivism and antagonism in immunosuppression. A critical review. Clin Exp Immunol 28:1-18.

Berenbaum MC (1989) What is synergy? Pharmacol Rev 41:93-141.
Bianchi MT and Macdonald RL (2003) Neurosteroids shift partial agonist activation of $\operatorname{GABA}(\mathrm{A})$ receptor channels from low- to high-efficacy gating patterns. $J$ Neurosci 23:10934-10943.

Brown AR, Herd MB, Belelli D, and Lambert JJ (2015) Developmentally regulated neurosteroid synthesis enhances GABAergic neurotransmission in mouse thalamocortical neurones. $J$ Physiol 593:267-284.

Cao LQ, Montana MC, Germann AL, Shin DJ, Chakrabarti S, Mennerick S, Yuede CM, Wozniak DF, Evers AS, and Akk G (2018) Enhanced GABAergic actions resulting from the coapplication of the steroid $3 \alpha$-hydroxy-5 $\alpha$-pregnane-11,20dione (alfaxalone) with propofol or diazepam. Sci Rep 8:10341.

Carter RB, Wood PL, Wieland S, Hawkinson JE, Belelli D, Lambert JJ, White HS, Wolf $\mathrm{HH}$, Mirsadeghi S, Tahir SH, et al. (1997) Characterization of the anticonvulsant properties of ganaxolone (CCD 1042; 3alpha-hydroxy-3betamethyl-5alpha-pregnan-20-one), a selective, high-affinity, steroid modulator of the gamma-aminobutyric acid(A) receptor. J Pharmacol Exp Ther 280: $1284-1295$.

Carver CM, Chuang SH, and Reddy DS (2016) Zinc selectively blocks neurosteroidsensitive extrasynaptic $\delta \mathrm{GABAA}$ receptors in the hippocampus. $J$ Neurosci 36 : 8070-8077.

Carver CM and Reddy DS (2013) Neurosteroid interactions with synaptic and extrasynaptic GABA(A) receptors: regulation of subunit plasticity, phasic and tonic inhibition, and neuronal network excitability. Psychopharmacology (Berl) 230: $151-188$

Carver CM and Reddy DS (2016) Neurosteroid structure-activity relationships for functional activation of extrasynaptic $\delta \mathrm{GABA}(\mathrm{A})$ receptors. $J$ Pharmacol Exp Ther 357:188-204.

Carver CM, Wu X, Gangisetty O, and Reddy DS (2014) Perimenstrual-like hormonal regulation of extrasynaptic $\delta$-containing GABAA receptors mediating tonic inhibition and neurosteroid sensitivity. J Neurosci 34:14181-14197.

Chen ZW, Bracamontes JR, Budelier MM, Germann AL, Shin DJ, Kathiresan K Qian MX, Manion B, Cheng WWL, Reichert DE, et al. (2019) Multiple functional neurosteroid binding sites on GABAA receptors. PLoS Biol 17:e3000157.

Chou TC and Talalay P (1983) Analysis of combined drug effects: a new look at a very old problem. Trends Pharmacol Sci 4:450-454.

Chuang SH and Reddy DS (2018a) Genetic and molecular regulation of extrasynaptic GABA-A receptors in the brain: therapeutic insights for epilepsy. J Pharmacol Exp Ther 364:180-197.

Chuang SH and Reddy DS (2018b) 3ß-Methyl-neurosteroid analogs are preferential positive allosteric modulators and direct activators of extrasynaptic $\delta$-subunit 
$\gamma$-aminobutyric acid type A receptors in the hippocampus dentate gyrus subfield. $J$ Pharmacol Exp Ther 365:583-601.

Chuang SH and Reddy DS (2019) Zinc reduces antiseizure activity of neurosteroids by selective blockade of extrasynaptic GABA-A receptor-mediated tonic inhibition in the hippocampus. Neuropharmacology 148:244-256.

Coulter DA and Carlson GC (2007) Functional regulation of the dentate gyrus by GABA-mediated inhibition. Prog Brain Res 163:235-243.

Czuczwar SJ and Przesmycki K (2001) Felbamate, gabapentin and topiramate as adjuvant antiepileptic drugs in experimental models of epilepsy. Pol J Pharmacol 53:65-68.

Earp J, Krzyzanski W, Chakraborty A, Zamacona MK, and Jusko WJ (2004) Assessment of drug interactions relevant to pharmacodynamic indirect response models. J Pharmacokinet Pharmacodyn 31:345-380.

Glykys J, Mann EO, and Mody I (2008) Which GABA(A) receptor subunits are necessary for tonic inhibition in the hippocampus? $J$ Neurosci 28 1421-1426.

Goldenberg MM (2010) Overview of drugs used for epilepsy and seizures: etiology, diagnosis, and treatment. $P \& T$ 35:392-415.

Gong QH and Smith SS (2014) Characterization of neurosteroid effects on hyperpolarizing current at $\alpha 4 \beta 2 \delta$ GABAA receptors. Psychopharmacology (Berl) 231: $3525-3535$.

Grabovsky Y and Tallarida RJ (2004) Isobolographic analysis for combinations of a full and partial agonist: curved isoboles. J Pharmacol Exp Ther $\mathbf{3 1 0}$ 981-986

Gunter BW, Jones SA, Paul IA, Platt DM, and Rowlett JK (2016) Benzodiazepine and neuroactive steroid combinations in rats: anxiolytic-like and discriminative stimulus effects. Psychopharmacology (Berl) 233:3237-3247.

Hesdorffer DC, Beck V, Begley CE, Bishop ML, Cushner-Weinstein S, Holmes GL, Shafer PO, Sirven JI, and Austin JK (2013) Research implications of the institute of medicine report, epilepsy across the spectrum: promoting health and understanding Epilepsia 54:207-216.

Hosie AM, Wilkins ME, and Smart TG (2007) Neurosteroid binding sites on GABA(A) receptors. Pharmacol Ther 116:7-19.

Jenkins A, Franks NP, and Lieb WR (1999) Effects of temperature and volatile anesthetics on GABA(A) receptors. Anesthesiology 90:484-491.

Jutila L, Immonen A, Partanen K, Partanen J, Mervaala E, Ylinen A, Alafuzoff I, Paljärvi L, Karkola K, Vapalahti M, et al. (2002) Neurobiology of epileptogenesis in the temporal lobe. Adv Tech Stand Neurosurg 27:5-22.

Kaminski RM, Livingood MR, and Rogawski MA (2004) Allopregnanolone analogs that positively modulate GABA receptors protect against partial seizures induced by $6-\mathrm{Hz}$ electrical stimulation in mice. Epilepsia 45:864-867.

Kwan P and Brodie MJ (2006) Combination therapy in epilepsy: when and what to use. Drugs 66:1817-1829.

Li P, Bracamontes JR, Manion BD, Mennerick S, Steinbach JH, Evers AS, and Akk G

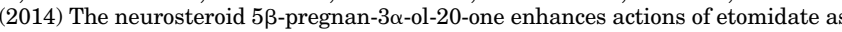
a positive allosteric modulator of $\alpha 1 \beta 2 \gamma 2 \mathrm{~L}$ GABAA receptors. $\mathrm{Br} J$ Pharmacol 171 : $5446-5457$.

Ligsay A, Van Dijck A, Nguyen DV, Lozano R, Chen Y, Bickel ES, Hessl D, Schneider A, Angkustsiri K, Tassone F, et al. (2017) A randomized double-blind, placebocontrolled trial of ganaxolone in children and adolescents with fragile X syndrome J Neurodev Disord 9:26-38.

Litchfield JT Jr and Wilcoxon F (1949) A simplified method of evaluating dose-effect experiments. J Pharmacol Exp Ther 96:99-113.

Loewe S (1953) The problem of synergism and antagonism of combined drugs. Arzneimittelforschung 3:285-290.

Łuszczki JJ (2008a) Interactions of tiagabine with ethosuximide in the mouse pentylenetetrazole-induced seizure model: an isobolographic analysis for nonparallel dose-response relationship curves. Naunyn Schmiedebergs Arch Pharmacol 378:483-492.

Łuszczki JJ (2008b) Isobolographic analysis of interaction between oxcarbazepine and valproate in pentylenetetrazole-induced seizures in mice. J Pre Clin Clin Res 2:40-45.

Łuszczki JJ and Czuczwar SJ (2004) Isobolographic profile of interactions between tiagabine and gabapentin: a preclinical study. Naunyn Schmiedebergs Arch Pharmacol 369:434-446.

Madsen KK, Clausen RP, Larsson OM, Krogsgaard-Larsen P, Schousboe A and White HS (2009) Synaptic and extrasynaptic GABA transporters as targets for anti-epileptic drugs. J Neurochem 109 (Suppl 1):139-144.

Maguire J and Mody I (2008) GABA(A)R plasticity during pregnancy: relevance to postpartum depression. Neuron 59:207-213.

Maguire JL, Stell BM, Rafizadeh M, and Mody I (2005) Ovarian cycle-linked changes in GABA(A) receptors mediating tonic inhibition alter seizure susceptibility and anxiety. Nat Neurosci 8:797-804.

Meldrum BS and Chapman AG (1999) Basic mechanisms of gabitril (tiagabine) and future potential developments. Epilepsia 40 (Suppl 9):S2-S6.

Meltzer-Brody S, Colquhoun H, Riesenberg R, Epperson CN, Deligiannidis KM, Rubinow DR, Li H, Sankoh AJ, Clemson C, Schacterle A, et al. (2018) Brexanolone injection in post-partum depression: two multicentre, double-blind, randomised, placebo-controlled, phase 3 trials. Lancet 392:1058-1070.

Mortensen M, Patel B, and Smart TG (2012) GABA Potency at GABA(A) receptors found in synaptic and extrasynaptic zones. Front Cell Neurosci 6:1-10.

Mtchedlishvili Z and Kapur J (2006) High-affinity, slowly desensitizing GABAA receptors mediate tonic inhibition in hippocampal dentate granule cells. $M o$ Pharmacol 69:564-575.
Nani F, Bright DP, Revilla-Sanchez R, Tretter V, Moss SJ, and Smart TG (2013) Tyrosine phosphorylation of GABAA receptor $\gamma 2$-subunit regulates tonic and phasic inhibition in the thalamus. $J$ Neurosci 33:12718-12727.

Nohria V and Giller E (2007) Ganaxolone. Neurotherapeutics 4:102-105

Nusser Z, Cull-Candy S, and Farrant M (1997) Differences in synaptic GABA(A) receptor number underlie variation in GABA mini amplitude. Neuron 19:697-709.

Oakley JC, Cho AR, Cheah CS, Scheuer T, and Catterall WA (2013) Synergistic GABA-enhancing therapy against seizures in a mouse model of Dravet syndrome. $J$ Pharmacol Exp Ther 345:215-224.

Papadopoulos V, Baraldi M, Guilarte TR, Knudsen TB, Lacapère JJ, Lindemann P, Norenberg MD, Nutt D, Weizman A, Zhang MR, et al. (2006) Translocator protein $(18 \mathrm{kDa})$ : new nomenclature for the peripheral-type benzodiazepine receptor based on its structure and molecular function. Trends Pharmacol Sci 27:402-409.

Patel AB, de Graaf RA, Rothman DL, and Behar KL (2015) Effects of $\gamma$-Aminobutyric acid transporter 1 inhibition by tiagabine on brain glutamate and $\gamma$-Aminobutyric acid metabolism in the anesthetized rat in vivo. $J$ Neurosci Res 93:1101-1108.

Pieribone VA, Tsai J, Soufflet C, Rey E, Shaw K, Giller E, and Dulac O (2007) Clinical evaluation of ganaxolone in pediatric and adolescent patients with refractory epilepsy. Epilepsia 48:1870-1874

Porcu P, Barron AM, Frye CA, Walf AA, Yang SY, He XY, Morrow AL, Panzica GC, and Melcangi RC (2016) Neurosteroidogenesis today: novel targets for neuroactive steroid synthesis and action and their relevance for translational research. $J$ Neuroendocrinol 28:12351.

Racine RJ (1972) Modification of seizure activity by electrical stimulation. II. Motor seizure. Electroencephalogr Clin Neurophysiol 32:281-294.

Reddy DS (2018) GABA-A receptors mediate tonic inhibition and neurosteroid sensitivity in the brain. Vitam Horm 107:177-191.

Reddy DS, Carver CM, Clossen B, and Wu X (2019) Extrasynaptic $\gamma$-aminobutyric acid type A receptor-mediated sex differences in the antiseizure activity of neurosteroids in status epilepticus and complex partial seizures. Epilepsia 60:730-743.

Reddy DS and Estes WA (2016) Clinical potential of neurosteroids for CNS disorders. Trends Pharmacol Sci 37:543-561.

Reddy DS and Mohan A (2011) Development and persistence of limbic epileptogenesis are impaired in mice lacking progesterone receptors. J Neurosci 31:650-658.

Reddy DS and Rogawski MA (2010) Ganaxolone suppression of behavioral and electrographic seizures in the mouse amygdala kindling model. Epilepsy Res 89:254-260.

Reddy DS and Rogawski MA (2012) Neurosteroids: endogenous regulators of seizure susceptibility and role in the treatment of epilepsy, in Jasper's Basic Mechanisms of the Epilepsies (Noebels JL, Avoli M, Rogawski MA, Olsen RW, and DelgadoEscueta AV eds) pp 984-1002, Oxford University Press, Bethesda, MD.

Reddy SD, Younus I, Clossen BL, and Reddy DS (2015) Antiseizure activity of midazolam in mice lacking $\delta$-subunit extrasynaptic GABA(A) receptors. $J$ Pharmacol Exp Ther 353:517-528.

Rupprecht R (2003) Neuroactive steroids: mechanisms of action and neuropsychopharmacological properties. Psychoneuroendocrinology 28:139-168.

Scimemi A, Andersson A, Heeroma JH, Strandberg J, Rydenhag B, McEvoy AW, Thom M, Asztely F, and Walker MC (2006) Tonic GABA(A) receptor-mediated currents in human brain. Eur J Neurosci 24:1157-1160.

Shin DJ, Germann AL, Covey DF, Steinbach JH, and Akk G (2019) Analysis of $\mathrm{GABA}_{\mathrm{A}}$ receptor activation by combinations of agonists acting at the same or distinct binding sites. Mol Pharmacol 95:70-81.

Shin DJ, Germann AL, Steinbach JH, and Akk G (2017) The actions of drug combinations on the $\mathrm{GABA}_{\mathrm{A}}$ receptor manifest as curvilinear isoboles of additivity. Mol Pharmacol 92:556-563.

Sun MY, Shu HJ, Benz A, Bracamontes J, Akk G, Zorumski CF, Steinbach JH, and Mennerick SJ (2018) Chemogenetic isolation reveals synaptic contribution of $\delta$ $\mathrm{GABA}_{\mathrm{A}}$ receptors in mouse dentate granule neurons. $J$ Neurosci 38:8128-8145.

Tallarida RJ (2000) Drug Synergism and Dose-Effect Data Analysis, Chapman \& Hall/CRC, Boca Raton.

Tallarida RJ (2006) An overview of drug combination analysis with isobolograms. $J$ Pharmacol Exp Ther 319:1-7.

Tallarida RJ (2007) Interactions between drugs and occupied receptors. Pharmacol Ther 113:197-209.

Thurman DJ, Beghi E, Begley CE, Berg AT, Buchhalter JR, Ding D, Hesdorffer DC, Hauser WA, Kazis L, Kobau R, et al.; ILAE Commission on Epidemiology (2011) Standards for epidemiologic studies and surveillance of epilepsy. Epilepsia $\mathbf{5 2}$ (Suppl 7):2-26.

Vicini S, Losi G, and Homanics GE (2002) GABA(A) receptor delta subunit deletion prevents neurosteroid modulation of inhibitory synaptic currents in cerebellar neurons. Neuropharmacology 43:646-650

Wojda E, Wlaz A, Patsalos PN, and Łuszczki JJ (2009) Isobolographic characterization of interactions of levetiracetam with the various antiepileptic drugs in the mouse $6 \mathrm{~Hz}$ psychomotor seizure model. Epilepsy Res 86:163-174.

Wu X, Gangisetty O, Carver CM, and Reddy DS (2013) Estrous cycle regulation of extrasynaptic $\delta$-containing GABA(A) receptor-mediated tonic inhibition and limbic epileptogenesis. J Pharmacol Exp Ther 346:146-160.

Address correspondence to: Dr. Doodipala Samba Reddy, Professor \& NIH CounterACT Investigator, Department of Neuroscience and Experimental Therapeutics, College of Medicine, Texas A\&M University Health Science Center, 8447 Riverside Parkway, MREB 2008, Bryan, TX 77807-3260. E-mail: sambareddy@tamu.edu 